\title{
Cellular responses to thermoresponsive stiffness memory elastomer nanohybrid scaffolds by 3D-TIPS
}

DOI:

10.1016/j.actbio.2018.12.019

\section{Document Version}

Accepted author manuscript

Link to publication record in Manchester Research Explorer

\section{Citation for published version (APA):}

Wu, L., Magaz, A., Maughan, E., Oliver, N., Darbyshire, A., Loizidou, M., Emberton, M., Birchall, M., \& Song, W. (2018). Cellular responses to thermoresponsive stiffness memory elastomer nanohybrid scaffolds by 3D-TIPS. Acta Biomaterialia. https://doi.org/10.1016/j.actbio.2018.12.019

\section{Published in:}

Acta Biomaterialia

\section{Citing this paper}

Please note that where the full-text provided on Manchester Research Explorer is the Author Accepted Manuscript or Proof version this may differ from the final Published version. If citing, it is advised that you check and use the publisher's definitive version.

\section{General rights}

Copyright and moral rights for the publications made accessible in the Research Explorer are retained by the authors and/or other copyright owners and it is a condition of accessing publications that users recognise and abide by the legal requirements associated with these rights.

\section{Takedown policy}

If you believe that this document breaches copyright please refer to the University of Manchester's Takedown Procedures [http://man.ac.uk/04Y6Bo] or contact uml.scholarlycommunications@manchester.ac.uk providing relevant details, so we can investigate your claim.

\section{OPEN ACCESS}




\section{Accepted Manuscript}

Full length article

Cellular responses to thermoresponsive stiffness memory elastomer nanohybrid scaffolds by 3D-TIPS

Linxiao Wu, Adrián Magaz, Elizabeth Maughan, Nina Oliver, Arnold

Darbyshire, Marilena Loizidou, Mark Emberton, Martin Birchall, Wenhui Song

PII:

S1742-7061(18)30744-X

DOI:

https://doi.org/10.1016/j.actbio.2018.12.019

Reference:

ACTBIO 5822

To appear in:

Acta Biomaterialia

Received Date: $\quad 3$ June 2018

Revised Date: $\quad 11$ November 2018

Accepted Date: $\quad 13$ December 2018

Please cite this article as: Wu, L., Magaz, A., Maughan, E., Oliver, N., Darbyshire, A., Loizidou, M., Emberton, M., Birchall, M., Song, W., Cellular responses to thermoresponsive stiffness memory elastomer nanohybrid scaffolds by 3D-TIPS, Acta Biomaterialia (2018), doi: https://doi.org/10.1016/j.actbio.2018.12.019

This is a PDF file of an unedited manuscript that has been accepted for publication. As a service to our customers we are providing this early version of the manuscript. The manuscript will undergo copyediting, typesetting, and review of the resulting proof before it is published in its final form. Please note that during the production process errors may be discovered which could affect the content, and all legal disclaimers that apply to the journal pertain. 


\title{
Cellular responses to thermoresponsive stiffness memory
}

\section{elastomer nanohybrid scaffolds by 3D-TIPS}

Linxiao $\mathrm{Wu}^{1}$, Adrián $\mathrm{Magaz}^{1 \dagger}$, Elizabeth Maughan ${ }^{2}$, Nina Oliver ${ }^{1}$, Arnold Darbyshire ${ }^{1}$, Marilena Loizidou ${ }^{1}$, Mark Emberton ${ }^{1}$, Martin Birchall ${ }^{2}$, Wenhui Song ${ }^{1 *}$

${ }^{1}$ Centre for Biomaterials in Surgical Reconstruction and Regeneration, Division of

Surgery \& Interventional Science, University College London, London, NW3 2PF,

United Kingdom

${ }^{2}$ UCL Ear Institute, Royal National Throat Nose and Ear Hospital and University

College London, London, United Kingdom

*Corresponding author, e-mail: w.song@ucl.ac.uk

${ }^{\dagger}$ Current address: Bio-Active Materials Group, School of Materials, The University of Manchester, Manchester, United Kingdom

\begin{abstract}
Increasing evidence suggests the contribution of the dynamic mechanical properties of the extracellular matrix (ECM) to regulate tissue remodeling and regeneration. Following our recent study on a family of thermoresponsive 'stiffness memory' elastomeric nanohybrid scaffolds manufactured via an indirect 3D printing guided thermo-induced phase separation process (3D-TIPS), this work reports in vitro and in vivo cellular responses towards these scaffolds with different initial stiffness and hierarchical interconnected porous structure. The viability of mouse embryonic dermal fibroblasts in vitro and the tissue responses during the stiffness softening of the scaffolds subcutaneously implanted in rats for three months were evaluated by immunohistochemistry and histology. Scaffolds with a higher initial stiffness and a hierarchical porous structure outperformed softer ones, providing initial mechanical support to cells and surrounding tissues before promoting cell and tissue growth during stiffness softening. Vascularization was guided throughout the digitally printed interconnected networks. All scaffolds exhibited polarization of the macrophage response from a macrophage phenotype type I (M1) towards a macrophage phenotype type II (M2) and down-regulation of the T-cell proliferative response with increasing implantation time; however, scaffolds with a more pronounced thermo-responsive stiffness memory mechanism exerted higher inflammo-informed effects. These results pave the way for personalized and biologically responsive soft tissue implants and implantable device with better mechanical matches, angiogenesis and tissue integration.
\end{abstract}

\section{Cellular responses to thermoresponsive stiffness memory elastomer nanohybrid scaffolds by 3D-TIPS}


Linxiao Wu ${ }^{1}$, Adrián Magaz ${ }^{1 \dagger}$, Elizabeth Maughan ${ }^{2}$, Nina Oliver ${ }^{1}$, Arnold Darbyshire ${ }^{1}$, Marilena Loizidou ${ }^{1}$, Mark Emberton ${ }^{1}$, Martin Birchall ${ }^{2}$, Wenhui Song ${ }^{1 *}$

\section{Statement of Significance}

This work reports cellular responses to a family of 3D-TIPS thermoresponsive nanohybrid elastomer scaffolds with different stiffness softening both in vitro and in vivo rat models. The results, for the first time, have revealed the effects of initial stiffness and dynamic stiffness softening of the scaffolds on tissue integration, vascularisation and inflammo-responses, without coupling chemical crosslinking processes. The 3D printed, hierarchically interconnected porous structures guide the growth of myofibroblasts, collagen fibres and blood vessels in real 3D scales. In vivo study on those unique smart elastomer scaffolds will help pave the way for personalized and biologically responsive soft tissue implants and implantable devices with better mechanical matches, angiogenesis and tissue integration.

\section{Keywords}

Stiffness memory, cellular response, 3D-TIPS, 3D printing, elastomer scaffold, inflammation modulation, angiogenesis

\section{Introduction}

Living tissues constantly remodel throughout life in response to dynamic stresses $[1,2]$ or injury $[3,4]$. For instance, heart valve interstitial cells have been found to respond to the local tissue stresses of hemodynamic flow by altering their cellular stiffness and matrix component biosynthesis [2]. Tissue healing of post-surgical implantation can involve even more dramatic changes of mechanical properties. For example, rib cartilage, typically used as an autologous cartilage source for tissue reconstruction, remodels its stiffness to match the surrounding tissues during the post-surgery healing 
process [4]. However, clinically available synthetic scaffolds and implants are often stronger and stiffer than the surrounding tissues. This may be due to the focus of most design and manufacture processes on optimizing biomaterials' mechanical stability, inertness and non-toxicity without consideration of how scaffolds are likely to adapt to stimuli in its implanted environment. On the other hand, early inflammation is common after implantation [5,6], stimulating a strong foreign body reaction and fibrosis response, resulting in disorganized collagen fibres and decreased tissue strength due to fibrous scar formation [1]. Healthy bone tissue often remodels in response to the stress change due to the mismatch of mechanical properties between a hard and stiff implant and the bone tissue, and becomes less dense and weaker, known as the stress-shielding effect $[7,8]$. In severe cases, this causes aseptic loosening of the implant in the absence of infection and can cause device or organ failure [9].

Advancements in surface topography and bulk modifications have paved the way to improving tissue integration of implants and scaffolds, and their implantation need not necessarily result in encapsulation. In particular, an appropriately porous structure can be an effective approach to maintaining a scaffold's material composition whilst reducing stiffness mismatch [10] and is essential to allow vascularization and tissue ingrowth within the scaffold. This in turn increases the degree of tissue integration with improved chances for long term fixation of the implants via biological anchorage [11]. It has been well recognized that the interface between a scaffold and the biological tissue determines the long-term in vivo integration of the implant $[6,12,13]$. However, the mechanobiological factors which contribute to the development and maintenance of a functional interface are not fully understood, largely due to biological variation and inaccessibility of the implantation site to mechanical study. Most biomaterial stiffness studies have been performed through chemical crosslinking using static in vitro cell culture conditions, which do not directly relate to the true in vivo dynamic environment. Little has been reported on the in vivo tissue responses to changes in scaffold stiffness or viscoelasticity.

The adult inflammatory response to surgical wounds is characterized by the recruitment of cells to the site of injury, phagocytosis of foreign bodies and the release of growth factors [6]. These stimulate cytokine secretion and initiate chemotaxis of neutrophils, macrophages, and fibroblasts, inducing granulation formation and ultimately leading to scarring [5,6]. Tissue healing of fetal cutaneous wounds, however, involves scarless wound repair [12,14-16], with neither the typical inflammatory response nor the scar tissue formation seen postnatally [5,13]. An ideal scaffold/implant would have the ability to alter both the surrounding environment and the cellular response to enhance positive tissue remodeling, integration and regeneration in and around it. Macrophage polarization (i.e. M1 to M2 macrophage phenotype) has been shown to regulate a regenerative versus fibrotic healing phenotype [17], and it has been reported that the mechanical properties of the scaffolds can influence scar formation via effects on the organization of fibroblasts infiltrating the wound bed and the subsequent orientation of deposited extracellular 
matrix (ECM) [18].

A family of thermoresponsive soft scaffolds, made from non-degradable poly(urea-urethane) (PUU) with nanocage chain ends of terminated polyhedral oligomeric silsesquioxane (PUU-POSS), had been developed recently using a 3D printing guided thermal-induced phase separation technique (3D-TIPS) [19]. The 3D-TIPS technique not only confers the 3D printing's capacity to design and manufacture complex 3D organ-like scaffolds and implants based on the patient's one anatomical dimensions [20,21], but also overcomes some limitations of conventional TIPS and 3D fused modelling printing, such as non-uniform porous structure, low resolution of pores and limitations in the availability of printable materials [22-25]. Uniform micro- to nano- pores were induced through the phase separation of the polymer solution within micro-channels of the 3D printed network of a negative sacrificial mould. In combination with digitally defined macro-pores, patient-specific scaffolds with multi-scale porous structures were produced by 3D-TIPS, a step closer to achieving the hierarchical structures presented in native ECM [22-25]. Furthermore, by taking advantages of the thermodynamic control of the phase separation, this 3D-TIPS approach allows the porous and phase structure of the polymer, and thus its properties, to be governed at micro- to nano-scales creating dual-level regulation of scaffold porosity and stiffness at different processing temperatures and post thermal treatment. These scaffolds with different stiffness and subsequent stiffness softening were achieved through microphase separation of PUU chains and crystallisation of soft segments during cryo-TIPS, following melting and reverse self-assembling at body temperature.

Here, 3D-TIPS scaffolds with different initial stiffness and hierarchical porous structures were further revealed during stiffness softening in vitro and in vivo. The viability of mouse embryonic dermal fibroblasts on the scaffolds in vitro was validated. Subcutaneous implantation in rat model provided evidence that the cellular response, including growth of tissue and blood vessel networks, and provoked inflammatory response to the scaffolds with varying starting stiffness and 3D interconnected porous structures were regulated by their stiffness softening.

\section{Materials and Methods}

\subsection{Fabrication of elastomer nanohybrid scaffolds}

PUU-POSS scaffolds were manufactured by an in-house 3D-TIPS technique. Briefly, PUU-POSS was synthesized as needed, adapted from a previously described protocol [26]. Poly (vinyl alcohol) (PVA) preforms were designed in OpenSCAD (v. 2015.03), exported as .stl files and sliced into consecutive $200 \mu \mathrm{m}$ layers with Slic3r (v. 9.9) for 3D printing with a $50 \%$ infill orthogonal density of resolution $400 \mu \mathrm{m} \times 400 \mu \mathrm{m}$. A PVA filament of $1.75 \mathrm{~mm}$ in diameter was extruded with a fusion deposition modelling (FDM) printer (Active X1; Active 3D Printers Ltd., UK) at $210^{\circ} \mathrm{C}$ at $150 \mathrm{~mm} . \mathrm{s}^{-1}$ for $\mathrm{X} / \mathrm{Y}$ printing speed and at $25 \mathrm{~mm} . \mathrm{s}^{-1}$ for $\mathrm{Z}$ printing speed. The nanohybrid polymeric solution was then injected through a surface punctured hole 
into the 3D printed PVA preforms, used as water soluble negative moulds. PUU-POSS was then coagulated at different conditions (Table 1): cryo-coagulation (50CC), cryo-coagulation and heating $(50 \mathrm{CC}+\mathrm{H})$, and room temperature coagulation and heating $(50 \mathrm{RTC}+\mathrm{H})$, following a previously described protocol [19].

Table 1 3D-TIPS processing conditions

\begin{tabular}{|c|c|c|c|}
\hline Scaffolds & $\begin{array}{c}\text { PUU-POSS } \\
\text { solution filled } \\
\text { PVA preform }\end{array}$ & $\begin{array}{c}\text { Coagulation } \\
\text { conditions }\end{array}$ & $\begin{array}{c}\text { Thermal } \\
\text { treatment }\end{array}$ \\
\hline $\begin{array}{c}\text { Room temperature } \\
\text { coagulation } \\
\text { theating, RTC+H }\end{array}$ & $\begin{array}{c}\text { Room } \\
\text { temperature, } \\
25^{\circ} \mathrm{C} \text { for } 24 \mathrm{~h}\end{array}$ & $\begin{array}{c}\text { Room temperature, } \\
25^{\circ} \mathrm{C} \text { water for } 24 \mathrm{~h}\end{array}$ & $40^{\circ} \mathrm{C}$ water for $3 \mathrm{~h}$ \\
\hline $\begin{array}{c}\text { Cryo-coagulation, } \\
\text { CC }\end{array}$ & $-20^{\circ} \mathrm{C}$ for $24 \mathrm{~h}$ & $0^{\circ} \mathrm{C}$ ice water for $24 \mathrm{~h}$ & $\begin{array}{c}\text { No thermal } \\
\text { treatment }\end{array}$ \\
\hline $\begin{array}{c}\text { Cryo-coagulation } \\
\text { +heating, } \mathrm{CC}+\mathrm{H}\end{array}$ & $-20^{\circ} \mathrm{C}$ for $24 \mathrm{~h}$ & $0^{\circ} \mathrm{C}$ ice water for $24 \mathrm{~h}$ & $40^{\circ} \mathrm{C}$ water for $3 \mathrm{~h}$ \\
\hline
\end{tabular}

\subsection{Characterization of structure of the scaffolds}

Static tensile mechanical properties of the scaffolds (preform size $12 \mathrm{~mm} \times 60 \mathrm{~mm} \times$ $6 \mathrm{~mm}$; $\mathrm{n}=6$ per group) before and after incubation at body temperature up to 28 days were tested at wet condition. Samples ( $\mathrm{n}=6$ per group) were subjected to uniaxial loads at $5 \mathrm{~mm} / \mathrm{min}$ using an Instron 5655 tester (Instron Ltd.; Norwood MA, USA) with a $500 \mathrm{~N}$ cell load, and ultimate tensile strength, strain at break and tensile modulus (between 0-50\% strain) were obtained from engineering stress-strain data generated by Bluehill ${ }^{\circledR}$ software. Toughness was calculated from the area under the graph for each sample and averaged.

The morphology of the surface and cross-section of the dried scaffolds ( $\mathrm{n}=2$ per group) were examined using a field emission scanning electron microscope (Zeiss Supra 35VP FE-SEM, Germany).

\subsection{In vitro experiments}

\subsubsection{Cell proliferation and viability}

Mouse embryonic dermal fibroblasts (3T3-J2 cells; Howard Green lab, Harvard University, 3T3-J2 CVCL_W667, USA) were cultured on tissue culture plastic in Dulbecco's modified Eagles medium (DMEM) supplemented with $10 \%$ foetal bovine serum (FBS) and $1 \%$ antibiotic $(50 \mu \mathrm{g} / \mathrm{mL}$ streptomycin, $50 \mu \mathrm{g} / \mathrm{mL}$ penicillin) solutions, and incubated at $37^{\circ} \mathrm{C}$. Polymer discs $(11 \mathrm{~mm}$ diameter and $1.5 \mathrm{~mm}$ thickness, $\mathrm{n}=4$ per group) were cut and sterilized in $70 \%$ ethanol and stirred for 30 min, air-dried in a sterile cell culture hood and finally washed in sterile phosphate-buffered saline (PBS). Discs were placed in 48-well plates and 
pre-incubated in $500 \mu \mathrm{l}$ of culture media for $24 \mathrm{~h}$ overnight.

Scaffolds were seeded with third-passage (P3) cells at a density of $9 \times 10^{4}$ cells $/ \mathrm{cm}^{3}$ $\left(1.3 \times 10^{4}\right.$ cells/scaffold) in $500 \mu 1$ of cell culture medium in 48 wells. Media was replaced every three days, and the metabolic activity was monitored on days 1, 3, 7, and 14 by the alamarBlue ${ }^{\circledR}(\mathrm{AB})$ assay (Serotec Ltd.; Kidlington, Oxford, UK) as per the manufacturer's instructions [27]. Total DNA content was also quantified at each time point using a fluorescent Hoechst 33258 stain [28].

\subsubsection{Extracellular collagen deposition}

The amount of extracellular acid-soluble collagen (types I-V) was measured in cells cultured on the scaffolds ( $\mathrm{n}=4$ per group) at days 1,3 and 7 . Cells were removed from scaffolds by trypsinization, centrifuged at $800 \times \mathrm{g}$ (centrifugal force) for $5 \mathrm{~min}$ with removal of supernatant and resuspended in $0.1 \%$ of $0.5 \mathrm{M}$ acetic acid, followed by three rinses in PBS. Samples were allowed to solubilize overnight. The quantity of acid-soluble collagen per sample in the extraction solution labelled with $0.1 \%$ Picro Sirus Red (PSR) solution (Sigma-Aldrich, UK) was measured using the Sircol ${ }^{\mathrm{TM}}$ assay (Biocolor, UK). Briefly, acid-soluble collagen, $100 \mu \mathrm{l}$ per sample, was added to $500 \mu \mathrm{l}$ of dye binding reagent and incubated at $37^{\circ} \mathrm{C}, 5 \% \mathrm{CO}_{2}$ for $1 \mathrm{~h}$ to form the insoluble dye-collagen complex solution. Dye-bound collagen was removed by centrifugation and the dye was then solubilized in alkaline and the absorbance of the resulting mixture was read at $540 \mathrm{~nm}$ on an absorbance plate reader (Anthos 2020; Biochrome Ltd, UK). The concentration of soluble collagen per sample was calculated from a standard curve of absorbance using bovine collagen standards kit $(\mathrm{n}=6)$. Results were normalized to the amount of collagen $(\mu \mathrm{g} / \mathrm{ml})$ in each sample.

\subsubsection{Immunohistochemistry by confocal microscopy}

Fibroblast cytoskeletal architecture and attachment were studied using FITC-labeled phalloidin (Life-technologies; Paisley, UK) according to the manufacturer's instructions. Briefly, cell-laden polymer discs ( $\mathrm{n}=3$ per group) were harvested at day 7 , fixed with 4\% (w/v) paraformaldehyde (PFA; Muto Pure Chemicals, Sigma-Aldrich, UK) in PBS for $12 \mathrm{~h}$ at $4{ }^{\circ} \mathrm{C}$ and rinsed with PBS. They were permeabilized with $0.1 \%$ Triton-X 100 (Sigma-Aldrich, UK) for 15 min, rinsed with PBS and blocked with $1 \%$ bovine serum albumin (BSA) in PBS solution for $30 \mathrm{~min}$. Following further rinsing, cells were stained with FITC-labelled phalloidin with nuclei counterstaining using a Propidium iodide (PI) (Sigma-Aldrich; Gillingham, UK). Images were taken using a confocal microscope (Leica TCS SP8vis, Germany) using a $\times 10$ water immersion objective lens. Z-stacked images were acquired by scanning 9-point areas $(3 \times 3)$ throughout $1.5 \mathrm{~mm}$ thickness of the scaffolds at $7 \mu \mathrm{m} / \mathrm{Z}$-step. Image stacks were visualized and analyzed using ImageJ software (Fiji, US), and 3D reconstructions were compiled from 214 imaged sections.

\subsubsection{Morphology of cell-seeded scaffolds}

Following three rinses with distilled water at day 7 , cell-laden scaffolds ( $\mathrm{n}=2$ per 
group) were dehydrated through a series of graded ethanol solutions and air-dried. Dried constructs were sputter-coated with gold and observed by SEM (Zeiss Supra 35VP FE-SEM, Germany).

\subsubsection{Histological analysis of cell-seeded scaffolds}

Cell-laden scaffolds ( $\mathrm{n}=2$ per group) were fixed in $4 \%$ PFA in PBS at day 7 , embedded in paraffin wax and cut into $4 \mu \mathrm{m}$ thick sections using a Leica RM2235 (Leica Microsystem Ltd., Milton Keynes, UK) microtome. Haematoxylin and eosin (H\&E) staining was performed to examine gross cell location and morphology.

\subsection{In vivo experiments}

\subsubsection{Scaffold implantation}

The in vivo study was conducted under a project license (70/7504) granted by the UK Home Office. Following sterilization in $70 \%(\mathrm{v} / \mathrm{v})$ ethanol, the scaffolds $(4 \mathrm{~cm} \times 4 \mathrm{~cm}$ $\times 2 \mathrm{~mm} ; \mathrm{n}=5$ per group) were subcutaneously implanted in adult male Sprague Dawley rats (Charles River Laboratories, UK) $(\mathrm{n}=30)$. All animals were kept in a temperature-controlled environment with a $12 \mathrm{~h}$ light/dark cycle and fed a laboratory diet and tap water ad libitum. The animals were preoperatively shaved, and ear marked accordingly, then anaesthetized with $4 \%$ isoflurane (induction) followed by $2 \%$ isoflourane (maintenance) by inhalation in combination with a $2: 1$ mixture of $\mathrm{O}_{2} / \mathrm{N}_{2} \mathrm{O}$. A single incision large enough to allow insertion of the scaffolds was made, then closed with subdermal interrupted sutures (Mersilk 3-0). The scaffolds were implanted slightlyposterior to the scapulae to prevent any disruption to motor function and/or discomfort. All animals were monitored on a daily basis.

No discomfort or attempts to dislodge the implants were observed. At 4, 8 and 12 weeks post-implantation, the rats were sacrificed by rising $\mathrm{CO}_{2}$ asphyxiation. The scaffolds were explanted and fixed in $10 \%$ CellStor Formal Saline for histological and material analysis.

\subsubsection{Characterization of the structure and mechanical properties of the explants}

Each explant ( $n=6$ per group) underwent tensile mechanical testing analysis using an Instron 5655 tester (Instron Ltd.; Norwood MA, USA). The average thickness to the nearest $0.01 \mathrm{~mm}$ was calculated from three thickness measurements for each specimen, and the properties of the scaffolds were tested in wet condition. Samples were subjected to uniaxial loads at $5 \mathrm{~mm} / \mathrm{min}$, and tensile modulus (between $0-50 \%$ strain), the ultimate tensile strength, strain at break and toughness were obtained from data generated by Bluehill ${ }^{\circledR}$ software based on engineering stress-strain data. Toughness was calculated from the area under the graph for each specimen and averaged.

The nanophase structure of the explants ( $\mathrm{n}=2$ per group) was examined via $\mathrm{X}$-ray diffraction (XRD Bruker D8 Advance, Germany).

\subsubsection{Histology and immunohistochemistry (IHC) assessments}


For histological sectioning, the explants were fixed in cold 4\% PFA (Sigma-Aldrich; Gillingham, UK) in PBS prior to scaffold sectioning and staining ( $\mathrm{n}=2$ per condition) for Hematoxylin and Eosin (H\&E) and Masson's trichome (M\&T) staining.

Collagen fibre formation and tissue ingrowth orientation were measured from tissue sections stained with H\&E and evaluated using ImageJ (NIH, USA) by analyzing low magnification images (refer to Figure D1 in Data in Brief). Immunofluorescent staining was also carried out to detect the presence of the capillary marker CD31, macrophage markers CD86/CD68 (macrophage phenotype type I, M1), CD163 (macrophage phenotype type II, M2) and T-cell makers CD3/CD4. Fresh scaffolds were washed in Dulbecco's phosphate-buffered saline (DPBS) and fixed in $10 \%$ neutral buffered formalin for 20 min. Samples were then permeabilized with $0.1 \%$ Triton X-100 (Sigma-Aldrich, UK) and blocked with 1\% BSA (Sigma-Aldrich, UK) in DPBS. They were then incubated with rabbit-anti CD31 antibody (1/100 dilution; Abcam, Cambridge, UK) or rabbit-anti CD68/CD86/CD163/CD3/CD4 antibodies (1/500 dilution; Abcam, Cambridge, UK) in $1 \%$ BSA in DPBS for $2 \mathrm{~h}$ at room temperature. A goat anti-rabbit Alexafluor ${ }^{\circledR}-594$ (1/500 dilution, Sigma-Aldrich, UK) in $1 \%$ BSA in DPBS was added for $1 \mathrm{~h}$ at room temperature. Rat liver was used as positive control against CD68+, CD86+ and CD163+ staining, while rat spleen was used as positive control against CD3+ and CD4+ staining. Negative control was rat appendix. Images were captured using a SPV8 confocal microscope (Leisca, Germany) at $\times 40$ magnification. Z-stacks were created with a $2 \mu \mathrm{m}$ distance between individual images. Z-stack image files were then read into IMARIS 7.6.3 analysis software (Bitplane Scientific, Switzerland) and were converted into three dimensional representations. The number of positive stained cells across the scaffold per unit volume was then quantified.

\subsection{Data analysis}

All quantitative data was presented as standard deviation (SD) of the mean values. Statistical analysis of the results was performed using Graph-Pad Prism 6 (GraphPad: San Diego, USA). For comparisons across more than two groups, statistical significance was calculated by two-way analysis of variance (ANOVA), with Tukey multiple comparison post-hoc analysis where a value of $\mathrm{p}<0.05$ was considered statistically significant.

\section{Results}

\section{1 'Stiffness memory' and hierarchical structures of 3D-TIPS scaffolds}

The thermoresponsive stiffness softening and hierarchical structures of the three groups of 3D-TIPS PUU-POSS scaffolds with different infilled densities at different processing conditions (Table 1) have been systematically studied and reported in our previous study [19]. Figure 1 and Table D1-D3 in Data in Brief highlight the correlation between the structure and mechanical properties by comparing the scaffolds with $50 \%$ infilled density as produced (day 0 ) and after incubation for 28 
days at $37^{\circ} \mathrm{C}$. The interconnected porous structures of in-plane and cross-section of the scaffold as produced were characterized by FE-SEM (Figure 1 A-C). The strut thickness of PUU-POSS scaffolds varied depending on the infill density and printing resolution of PVA preform. In the case of $50 \%$ infill density and $200 \mu \mathrm{m}$ slicing thickness of PVA mould, the average thickness of the strut of the scaffold in-plane (xand $\mathrm{y}$-axis) is between 175- $197 \mu \mathrm{m}$ and $\mathrm{z}$-axis between $118-127 \mu \mathrm{m}$, with various tolerances depending on the processing conditions as listed in Table D2 in Data in Brief. It is also clear to see that the digitally printed macro-pore size in-plane is consistent with the printing resolution of PVA struts inside of the negative mould, around $400 \mu \mathrm{m} \times 400 \mu \mathrm{m}$ in $\mathrm{x}$ and y axes (Figure 1 A1-C1) and in cross-section with $400 \mu \mathrm{m} \times 200 \mu \mathrm{m}$ in $\mathrm{x}$ and z-axes (Figure 1 A3-C3), with variations for each type of the scaffold depending on the processing conditions. More micro- to nano-pores were generated during cryo-3D-TIPS process as shown in Figure 1 A2-C2. The pore size, size distribution, surface area and porosity of the hierarchical porous structures of the scaffolds were measured by mercury intrusion porosimetry previously and summarized in Table D3 [19] in Data in Brief. 50CC scaffolds consist of the most pores at multiscale ranging from macro, micro- to nanometers with the highest porosity $(98.3 \%)$ and surface area $\left(58.5 \mathrm{~m}^{2} / \mathrm{g}\right)$, which is supported by the uniform spherulite-like bead morphology (Figure 1 A1, A2). 50CC + H scaffolds (Figure 1 B1, B2) are similar to 50CC but with some decrease of pores at micro- and nano-scale because of the shrinkage occurred during the thermal treatment (Table 2D in Data in Brief). 50RTC $+\mathrm{H}$ scaffolds consist of the least of micro- and nano-pores, with the same porosity to 50CC, and thus a much lower surface area $\left(4.6 \mathrm{~m}^{2} / \mathrm{g}\right)$, in evidence of the dense skin effect due to faster coagulation at the surface at room temperature (Figure 1 C1, C2).

The significant reductions of tensile modulus (46\%) and strength $(57 \%)$ of the 50CC group with initial high stiffness on day 28 demonstrate pronounce viscoelastic behavior, resulting in stiffness softening in response to the incubation body temperature (Figure 1D), opposed to the stress and strain profiles for $50 \mathrm{CC}+\mathrm{H}$ and 50RTC+H (Figure 1E-F).

Regardless the initial stiffness produced at different thermal process conditions, PUU-POSS scaffolds 'remembered' to relax to their intrinsic hyperelastic rubber phase (Figure 1 D-F) when subjected to body temperature, close to the melting temperature of the soft segments $\left(\mathrm{Tm}=45^{\circ} \mathrm{C}\right)$ [19]. In fact, this stiffness softening was driven by two stages of thermodynamic phase transition and local chain self-assembly: the $1^{\text {st }}$ order phase transition due to the melting of semicrystalline soft domain, followed by a low-dimensional and short-distance inverse self-assembly of the nanostructures towards a quasi-random nanophase crossing over a wide range of chain relaxation times [19]. Despite the difficulty to reproduce the same semicrystal structure from the polymer solution by the 3D-TIPS process, this chain relaxation process is still thermodynamically favoured for the soft segments to re-crystallisation or densely packing from the rubber phase at a suitable temperature, below the $T_{m}$ 
$\left(42^{\circ} \mathrm{C}\right)$ and above $\mathrm{T}_{\mathrm{g}}\left(-30\right.$ to $\left.-34^{\circ} \mathrm{C}\right)$. Therefore, in principle, such 'stiffness memory' may be reversible or partially reversible despite the fact that it is kinetically slow in the solid state.

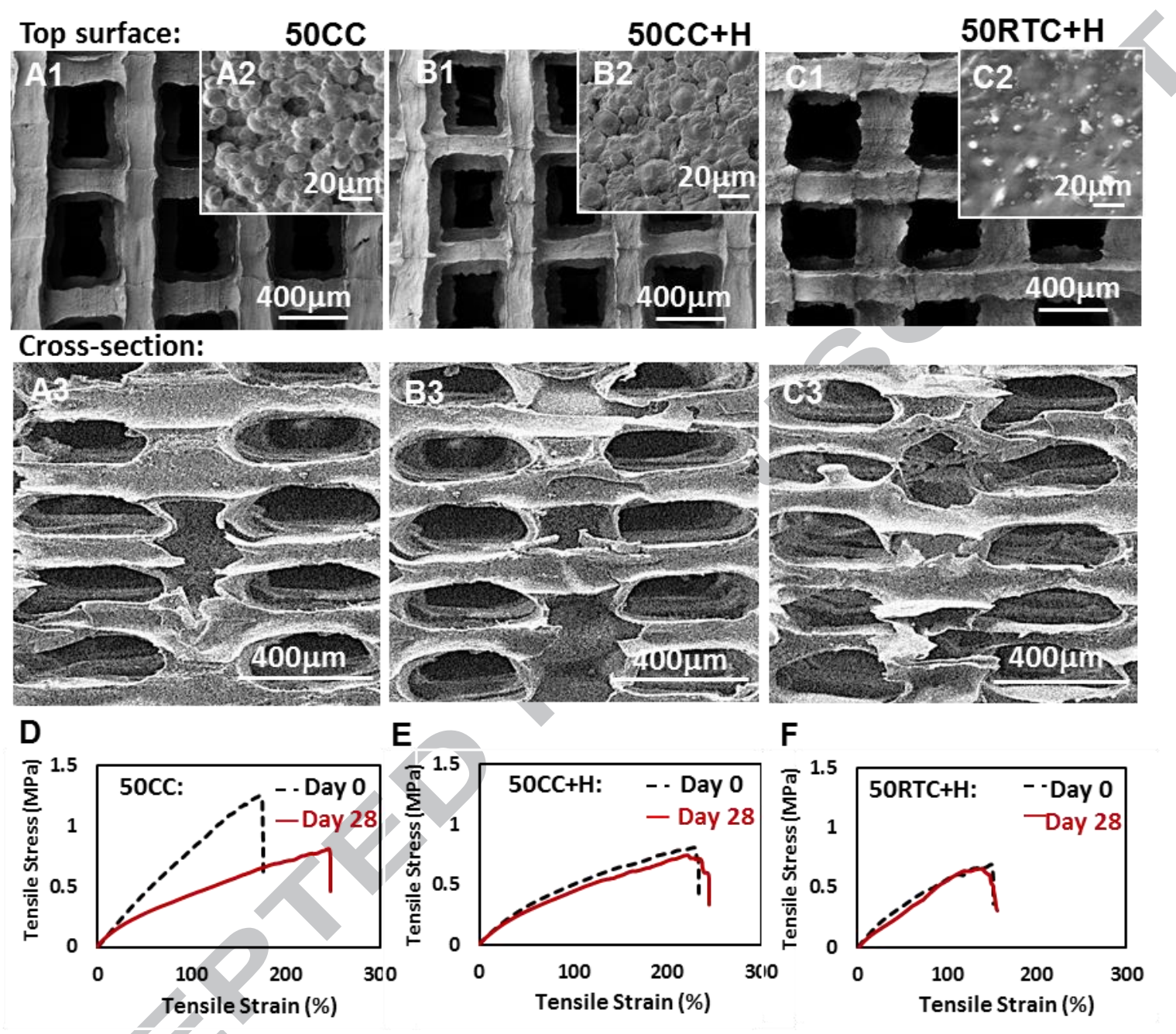

Figure 1 'Stiffness memory' and corresponding structure of PUU-POSS scaffolds by 3D-TIPS at different thermal conditions: (A-C) SEM images of morphology of top surface and cross-section of the as-produced scaffolds (insets showing higher magnification); (D-F) Stress-strain curves showing stiffness softening mechanism at day 0 and after 28 days in vitro incubation.

\subsection{In vitro cellular response to stiffness softening of 3D-TIPS scaffolds}

PUU-POSS scaffolds were seeded with embryonic mouse 3T3-J2 fibroblasts to investigate the in vitro cellular response to the scaffolds prior to implantation. Cells exhibited greater metabolic activity and proliferation on 50CC scaffolds, with the highest initial tensile modulus (Table D1 in Data in Brief, Figure 1 A) and the most hierarchical porous structure (Table D3 in Data in Brief), compared to the rest of the groups $(\mathrm{p}<0.01)$, as seen by alamarBlue and totalDNA assays over the course of 14 days (Figure 2 A-B). The content of extracellular collagen per cell (Figure 2 C) also remained significantly $(\mathrm{p}<0.01)$ higher on the $50 \mathrm{CC}$ group at all day points, followed 
by the $50 \mathrm{CC}+\mathrm{H}$ sample. Furthermore, confocal microscopy at day 7 confirmed greater cellular activity and organization in 50CC scaffolds as seen by immunofluorescent staining and 3D reconstructions of fluorescent intensity (Figure 2 D-F). SEM images at day 7 (Figure 2 D4-F4) show well-spread morphologies of typical fibroblasts attached on the scaffold surface, and histological images by H\&E staining of the cross section of the scaffolds at day 7 (Figure 2 D5-F5) indicate good integration of the cells within the porous network, most prominently in the 50CC scaffold. By day 14, both cell metabolic activity and total DNA decreased after reaching confluence. 

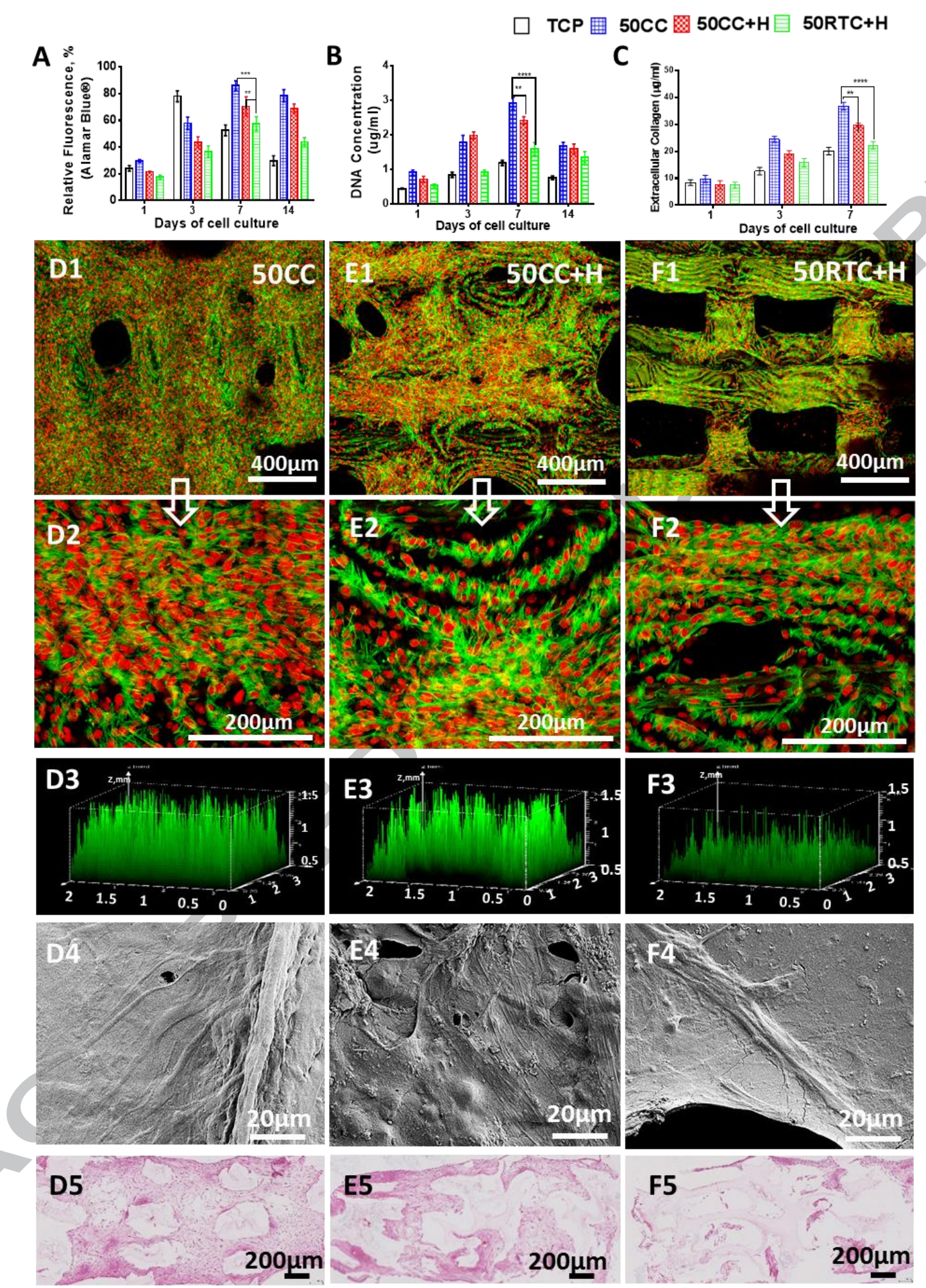

Figure 2 In vitro cellular response of Mouse 3T3-J2 cells to PUU-POSS scaffolds by 3D-TIPS with different thermal process conditions. (A) alamarBlue fluorescence assay, (B) total DNA analysis, and (C) extracellular acid-soluble collagen (types I-V) deposition. Confocal microscopy images $(\times 10$ and $\times 20$ objective lens) at day 7 with cells stained for $\mathrm{f}$-actin (green) and counterstained nuclei (red) for (D1-D2) 50CC, (E1-E2) 50CC+H and (F1-F2) 50RTC+H. (D3-F3) 3D 
reconstructions of fluorescence light intensity by confocal microscopy at day 7 . (D4-F4) SEM images of cell attachment and morphology at day 7. (D5-F5) Histological images of the cross sections of the scaffold at day 7 by H\&E staining. $* * \mathrm{p}<0.01 ; * * * \mathrm{p}<0.001 ; * * * * \mathrm{p}<0.0001$; errors bar in SD.

\subsection{In vivo results}

\subsubsection{Effect of the scaffolds on cellular infiltration and matrix deposition during} in vivo implantation

The scaffolds were subcutaneously implanted under the rat back skin (Figure 3 A-C) for up to 12 weeks. The static tensile elastic modulus, tensile strength, strain at break and toughness of explanted scaffolds (Figure 3 D-G, Tables D4-D7) calculated from stress-strain curves (Figure $3 \mathbf{H}-\mathbf{J}$ ) were shown proportional increases at all three time points tested due to reinforcement by tissue ingrowth (Figure 3 A-C). The 50CC scaffolds exhibited the highest mechanical properties at all time points, but non-significant differences were found between the groups at week 12 after their stiffness relaxation. The crystalline structure of the explants was evaluated at weeks 4, 8 and 12 with XRD (Figure 3 K-M, Table D8 in Data in Brief). Before implantation, the CC scaffold presented two sharp Bragg diffraction peaks at $2 \theta=20^{\circ}$ and $23.4^{\circ}$, and one broader halo peak at around $19.9^{\circ}$, with inter-planar spacing (d-spacing) of 0.44 $\mathrm{nm}$ and $0.38 \mathrm{~nm}$, as the lateral distance in the interfaces of crystallized soft segments. For the $\mathrm{CC}+\mathrm{H}$ group, the ordered crystal lattice structure almost disappeared, relaxing the long-distance order to a quasi-random amorphous structure with a similar diffraction profile to that of the $\mathrm{RTC}+\mathrm{H}$ group (comprising three broad halo peaks, including a broadening halo peak at $2 \theta=19.9^{\circ}$ and a shoulder apparent at an approximately lower angle of $2 \theta=12.0^{\circ}$ ). After 3 months of in vivo implantation, all scaffolds exhibited similar XRD spectrum after stiffness relaxation, where the more pronounced spectra halo peaks from all explants echoed the unique thermodynamically stable nanophase structure of the nanohybrid's rubber phase, in agreement with the results in vitro in Figure 1. 


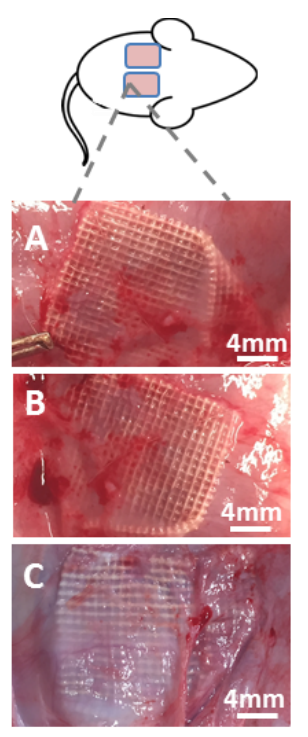

H
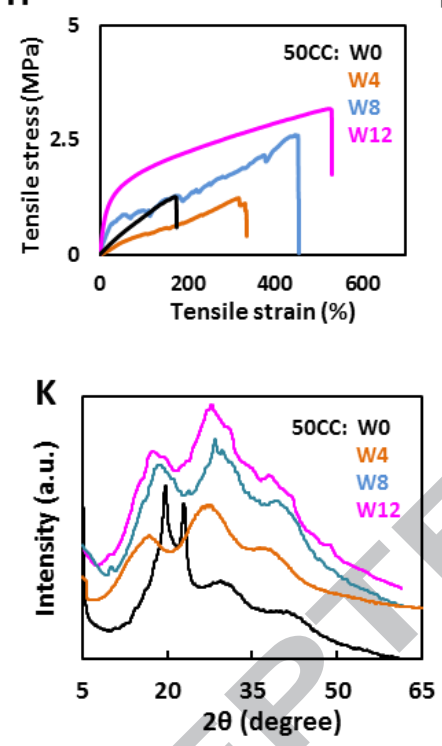

D
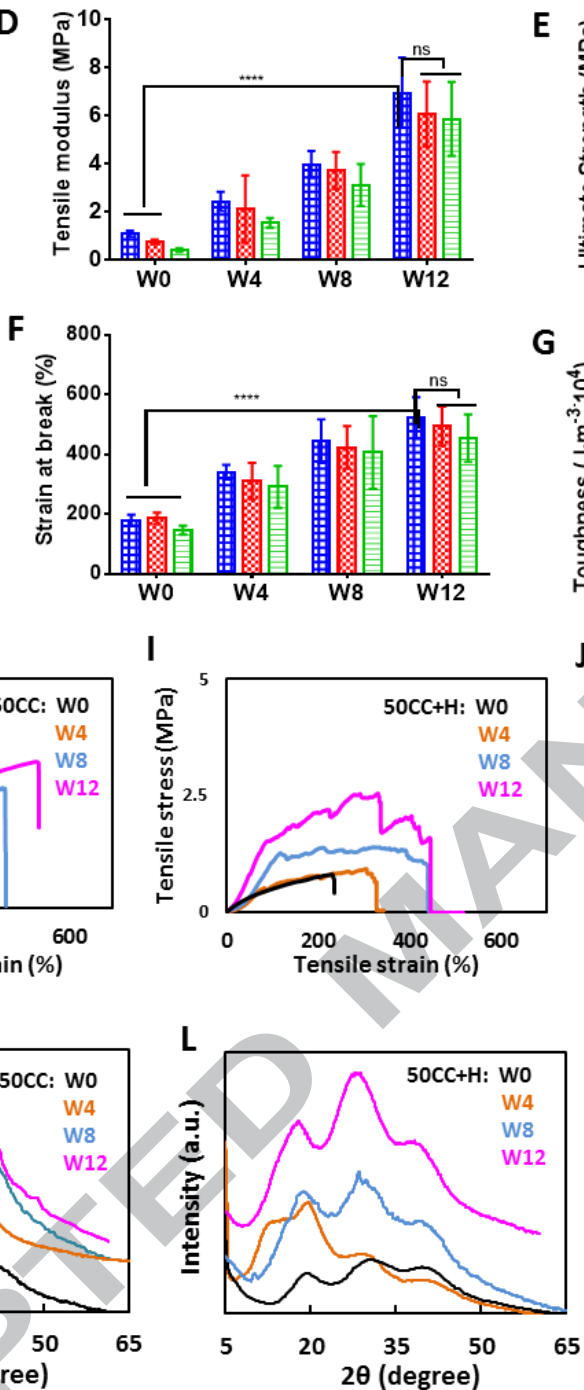

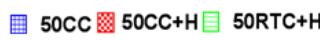

E

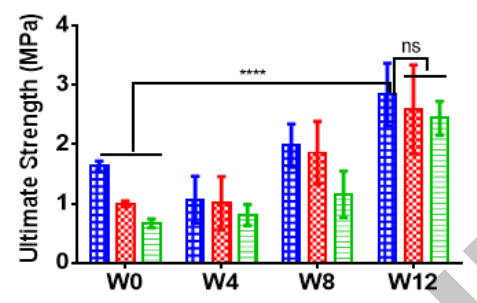

G
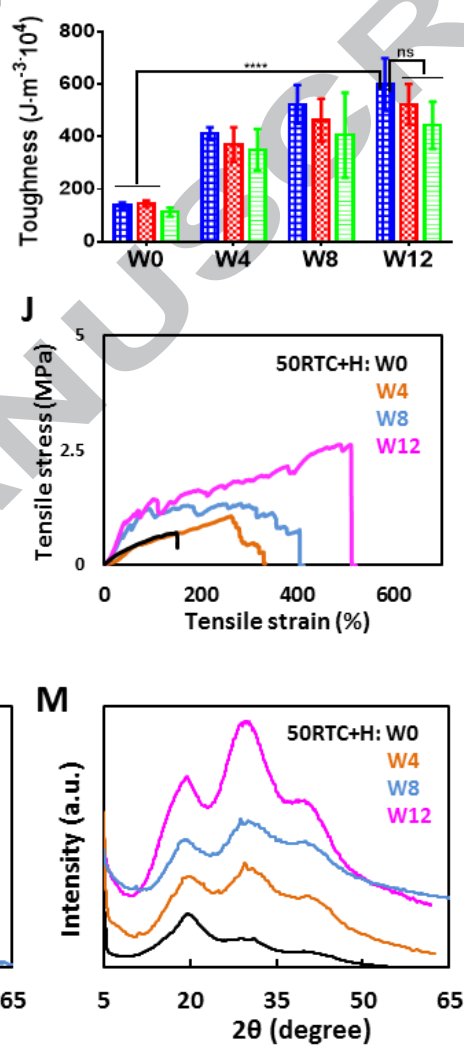

Figure 3 Physico-mechanical characterization of PUU-POSS explants by 3D-TIPS with different thermal process conditions (A-C) Scaffolds explants (50\% infill density) after implantation for 12 weeks: (A) $50 \mathrm{CC}$, (B) $50 \mathrm{CC}+\mathrm{H}$, and (C) 50RTC+H. (D-J) Mechanical characterization of the scaffolds before and after implantation for weeks 4, 8 and 12: (D) tensile modulus (at 50\% strain), (E) ultimate tensile strength (breaking point), (F) strain at break, (G) toughness, and (H-J) stress-strain curves; (K-M) XRD spectra of the explants before and after implantation for weeks 4, 8 and 12. ****p $<0.0001$, errors bar in SD.

H\&E staining and M\&T of subcutaneously implanted scaffolds revealed good ingrowth of tissue in all scaffold types throughout their interconnected porous networks (Figure 4 A-L, Figures D1-D3 in Data in Brief). The thickness of the aligned tissue ingrowth within the various scaffolds was quantified after implantation at weeks 4, 8 and 12 (Figure 4 M, Figure D1 in Data in Brief). Faster and greater amount of aligned ingrowth tissue was reported on the 50CC scaffold compared to the rest of the groups $(\mathrm{p}<0.001)$. 
Internal hydrostatic pressure was applied to the scaffolds once implanted, due to bending confinement under the rat back skin, with a combination of compression and tension stresses distributed within them as illustrated in Figure 5 A-B. This is reflected by the obvious deformation of the polymer macrostructure in histological samples in combination with matrix deposition and tissue infiltration (Figure 4, Figures D1-D3 in Data in Brief). Consequently, tissue ingrown following the digitally printed geometry of the interconnected tunnels (left by dissolution of the printed PVA network) in response to their local microenvironment. Figure 5 C-N shows some typical H\&E stained structures of the ingrown tissue in response to the geometry of the macro- to micro-porous structure and possible local stresses distributed. At the vertical pore junctions of the tunnels (i.e. cross junction of printed PVA struts), new tissue grew around the wall with concentric circularly aligned microfilament bundles (i.e. elongated myofibroblast and collagen fibres), whereas most microvascular vessels grew perpendicularly through the less aligned central tissue (Figure 5 C-E). Despite the printed symmetric orthogonal pattern, the short and long dumbbell-shaped ingrown tissues between two junctions appeared and showed distinctly different orientations of myofibroblasts and collagen fibres, with either perpendicular (Figure 5F) or parallel alignment with respect to the tunnels (Figure 5 I, L). Such different confinement may be induced by the local stress conditions of the scaffold, where tensile stress stretched the struts while the compression shortened the distance of the channels. In addition, the long dumbbell tissue grew relatively slower compared with the concentric areas at the earlier (4-week) time point, perhaps due to a less efficient transport of nutrients through the elongated tunnel horizontally (Figure $5 \mathbf{E}, \mathbf{H}, \mathbf{K}$ and $\mathbf{N})$. At 12 weeks, the minimum diameter $\left(\mathrm{D}_{\min }\right)$ of ingrown tissue was the largest in the 50CC scaffold group and smallest in the 50CC+H group, consistent with the original micro/macropore diameters of the scaffolds in Table D2-D3 in Data in Brief. 

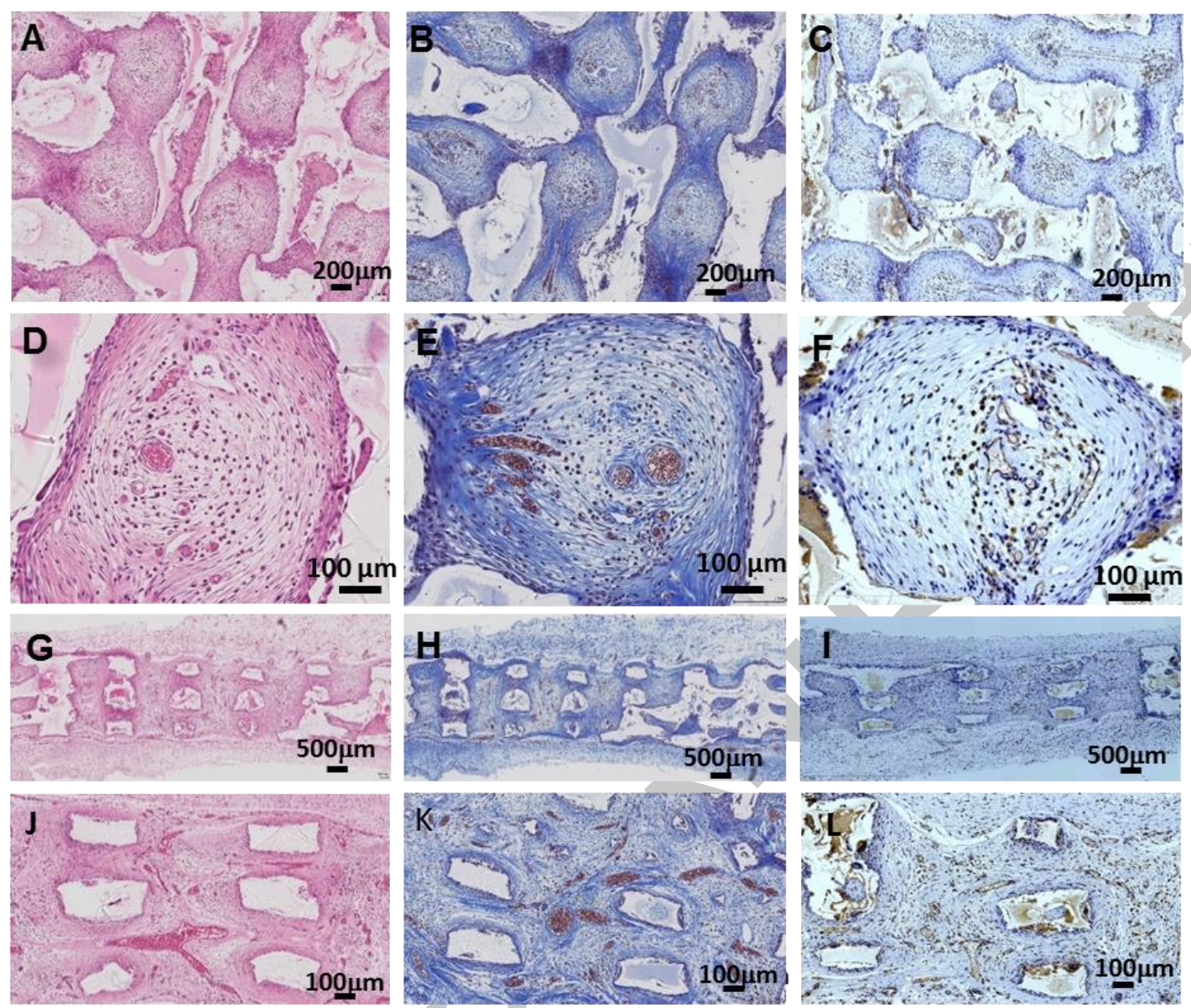

M

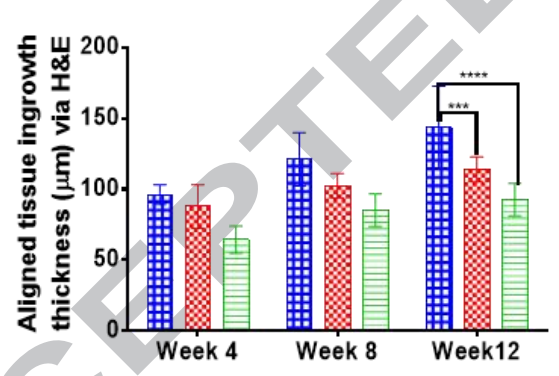

N

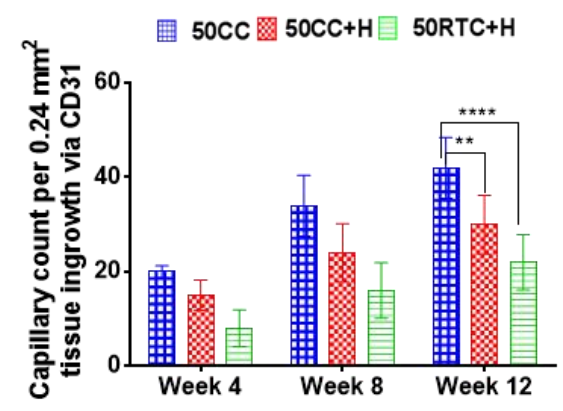

Figure 4 Cellular infiltration and matrix deposition in PUU-POSS scaffolds produced by different thermal process conditions of 3D-TIPS after subcutaneous implantation for a week 12: (A) tissue integration of middle-in-plane by Hematoxylin and Eosin (H\&E) staining; (B) collagen production by Masson's trichome (MT) staining; (C) endothelial cell infiltration as identified by CD31 staining, which is used as a marker of angiogenesis, and (D-F) enlarged views respectively. (G-I) Middle cross-sectional view and (J-L) enlarged view of the 50CC scaffolds, respectively stained by H\&E, MT and CD31. (M-N) Quantification of cellular integration and growth by 4 and 12 weeks of the various scaffolds (M) thickness of aligned tissue ingrowth (refer to Figure S2); (N) capillary infiltration density of ingrowth tissue. $* * \mathrm{p}<0.01, * * * * \mathrm{p}<0.0001$, errors bar in SD; $(\mathrm{n}=12, \times 4$, from four scaffolds in each group at each time point). 

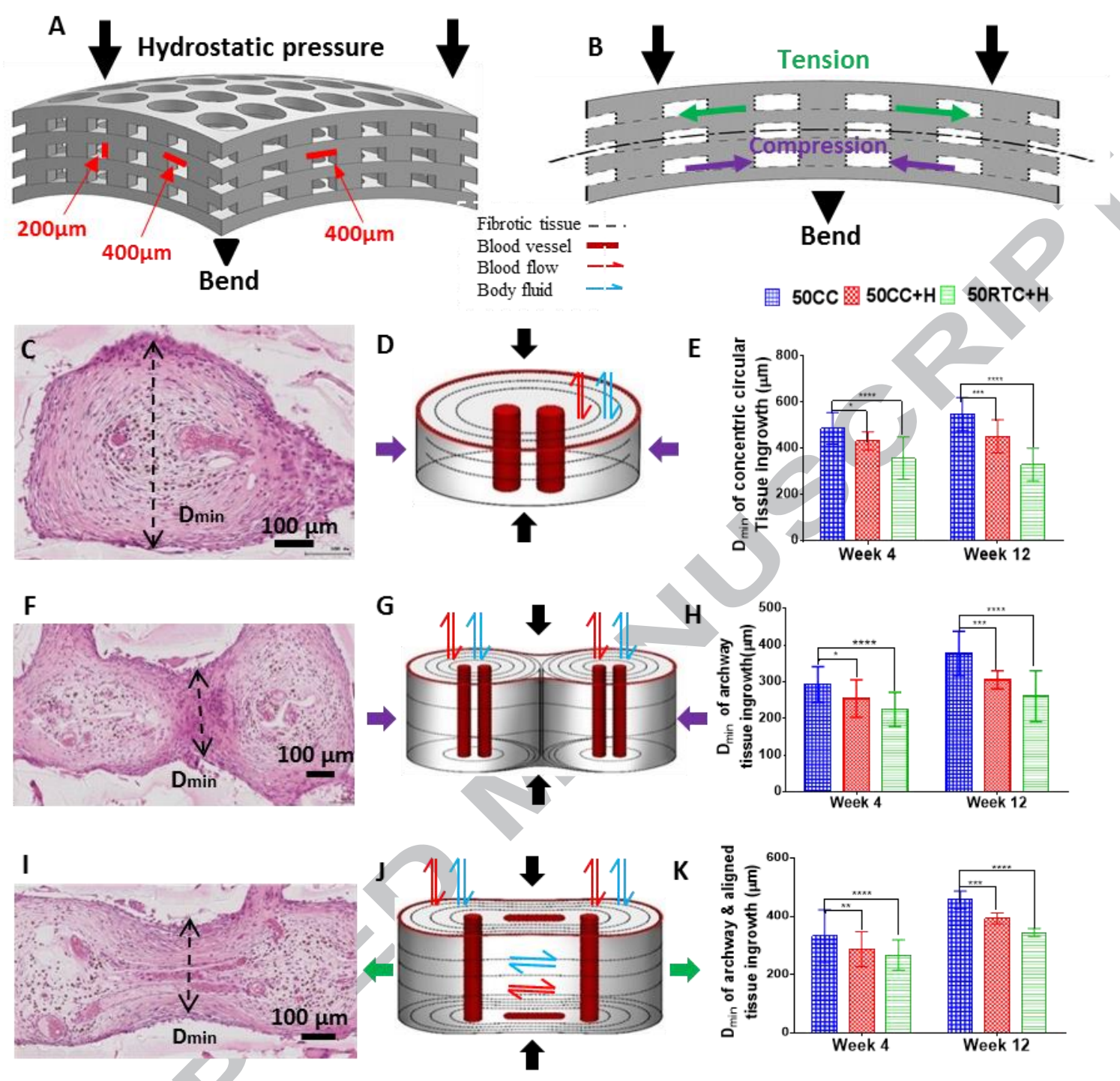

L

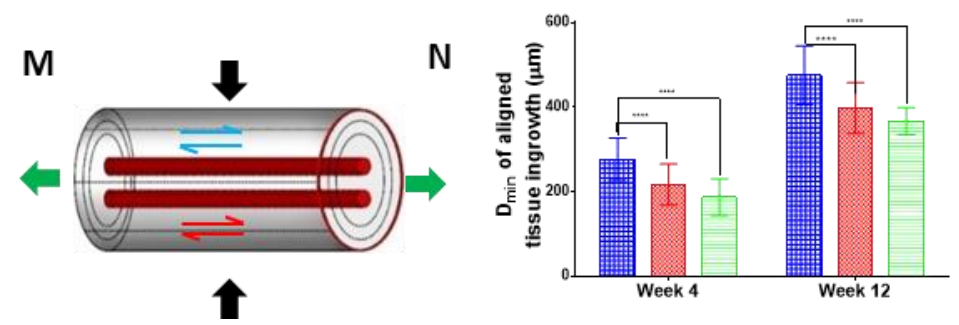

Figure 5 Tissue ingrowth within the network of PUU-POSS scaffolds by 3D-TIPS with different thermal processing conditions at weeks 4 and 12 in vivo: (A) Schematic diagram of bend loading condition of the implanted scaffold due to hydrostatic pressure under the rat skin; (B) stress distribution of compression and tension across the scaffold cross-section under bending load; (C-N) H\&E histological structure and schematic diagrams of stress condition and statistical analysis of the ingrowth of tissue; $(\mathrm{C}, \mathrm{D}, \mathrm{E})$ concentric aligned tissue at the junction of the scaffold; (F, G, H) short dumbbell tissue with the compressed channels; (I, J, K) long dumbbell tissue between the elongated channel; ( $\mathrm{L}, \mathrm{M}, \mathrm{N})$ aligned tissue in long tunnels. $* \mathrm{p}<0.05 ; * * * \mathrm{p}<0.001, * * * * \mathrm{p}<0.0001$, errors bar in SD $(\mathrm{n}=10$, four scaffolds in each 
group at each time point).

\subsubsection{Effect of stiffness memory on vascularization in vivo}
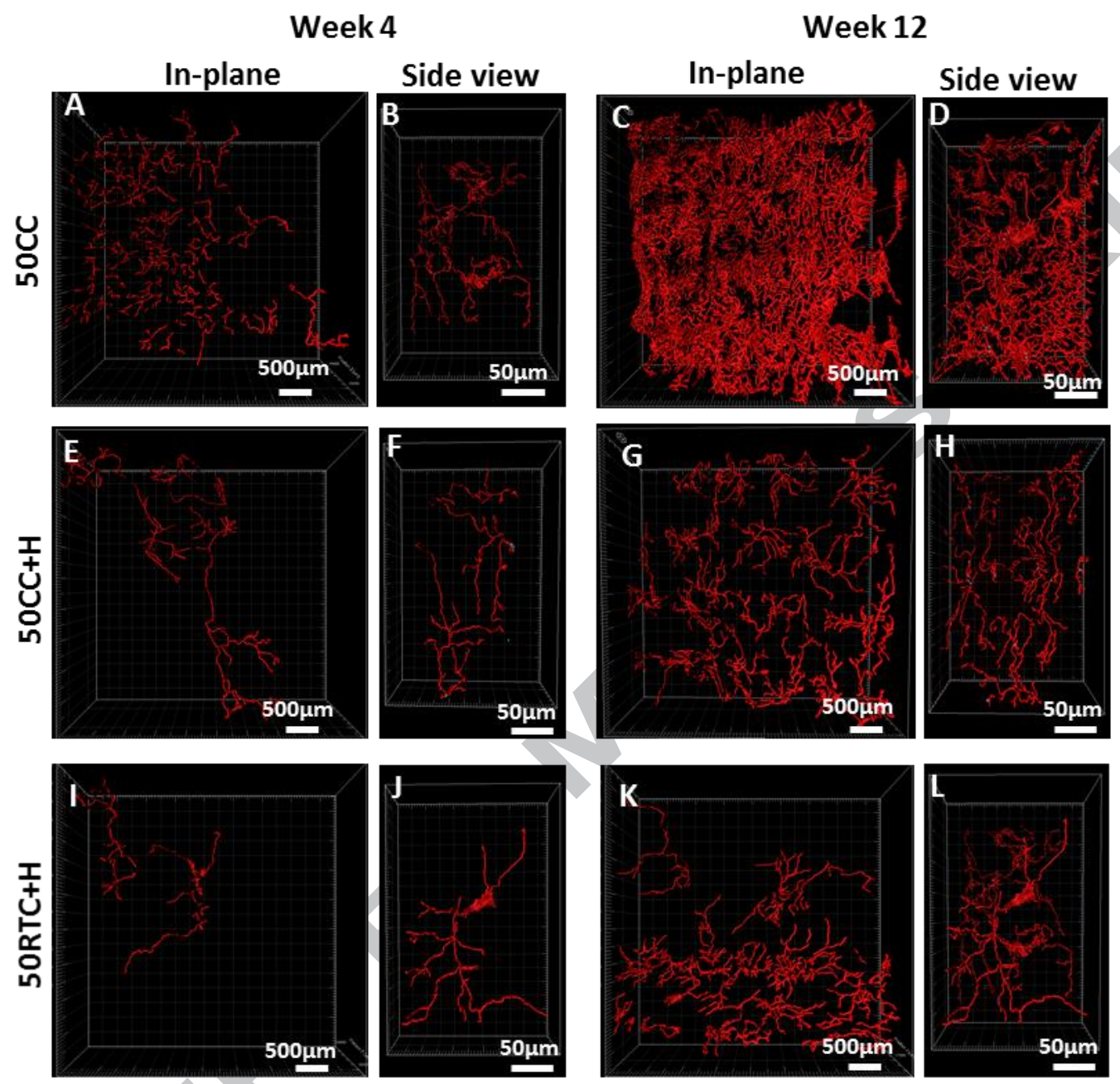

M

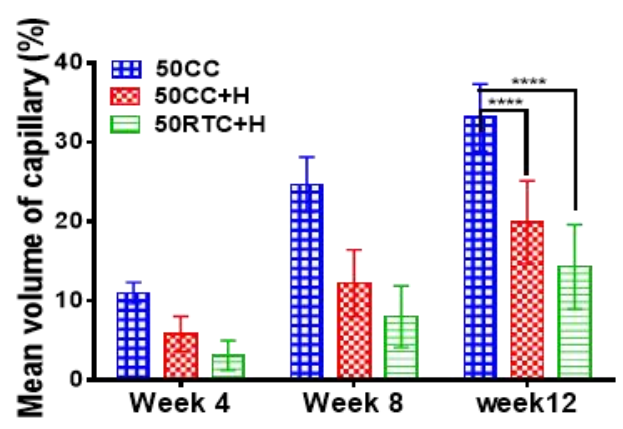

Figure 6 Angiogenesis in PUU-POSS scaffolds by 3D-TIPS with different thermal processing conditions. (A-L) 3D image reconstruction of immunofluorescent staining of anti-CD31 marker for blood capillaries at weeks 4 and 12 for the various scaffolds. (M) Mean volume fraction of blood capillaries of the total tissue/scaffold volume at weeks 4,8 and 12. ****p<0.0001, errors bar in SD $(n=10$, four scaffolds in each group at each time point). 
Ingrowth of blood capillaries were clearly visualized within the implanted scaffolds as early as 4 weeks post implantation and continued to increase until 12 weeks after implantation, as demonstrated by anti-CD31 immunofluorescence (Figure 6 A-L). The capillary volume fraction (CVF), i.e. the volume of blood capillaries occupied within the overall volume of the scaffold, was used to compare the functionality of the angiogenic response of the host towards the 3D scaffolds in each group (Figure $6 \mathbf{M}$ ). The CVF increased from week 4 towards week 12 for each scaffold group. Higher CVF values were observed in the 50CC group compared with the rest of the scaffolds $(\mathrm{p}<0.0001)$ at all time points. This is consistent with a greater capillary infiltration density of ingrowth tissue for the 50CC group (Figure $4 \mathbf{C}, \mathbf{N}$ ). The 50RTC $+\mathrm{H}$ group exhibited the smallest CVF (Table D9 in Data in Brief).

\subsubsection{Effect of 'stiffness memory' on the macrophage and T-cell proliferative responses in vivo}

The effect of the scaffolds towards macrophage activation and polarization was studied by immunohistochemistry with markers against CD68+ and CD86+ (M1 pan-macrophage/monocyte marker and macrophage marker), and CD163+ cell subsets (M2 phenotype). Macrophages are plastic cells and the M1/M2 phenotype is widely used to distinguish between different macrophage activation states. The M1 macrophage phenotype (classically activated macrophage) is known to induce prototypic inflammatory responses; in contrast, cells of the M2 phenotype (alternatively activated macrophages) can antagonize prototypic inflammatory responses. All implanted scaffolds in vivo were able to modulate the inflammatory reaction by driving the macrophage response (Figure 7). In particular, there was a decrease in the density of CD68+ and CD86+ cells in the surrounding tissue with increasing time periods (Figure 8 A-B, Tables D10-D11 in Data in Brief), with a significant reduction within all scaffold groups from week 4 (Figures D4, D6 in Data in Brief) towards week 12 (Figures D5, D7 in Data in Brief) $(\mathrm{p}<0.01 \mathrm{CD} 68+$ and $\mathrm{p}<0.001 \mathrm{CD} 86+$ ). Conversely, an increase in the density of CD163+ cells (M2 phenotype) (Figure 8 C, Table D12 in Data in Brief) was observed at week 12 (Figure D9 in Data in Brief) compared to week 4 (Figure D8 in Data in Brief). By computing the macrophage polarization ratio $\mathrm{M} 1 / \mathrm{M} 2$ (i.e. Figure 8 D-E in terms of CD68+/CD163+ and CD86+/CD163+ respectively, Tables D13-D14 in Data in Brief), which determines the inflammatory vs. reparative potential during implantation of the scaffold, it was significantly lower for both the 50CC and 50CC+H groups (p-value non-significant) compared to the 50RTC $+\mathrm{H}$ samples $(\mathrm{p}<0.0001)$ for all time points.

The T-cell proliferative response of the scaffolds after implantation was also studied by immunohistochemistry with markers against cell subsets CD3+ and CD4+. The corresponding numerical density histogram (Figure 8 F-G, Tables D15-D1 in Data in Brief) indicates a decrease in the CD3+ and CD4+ T-cell proliferative response within all scaffold groups from week 4 (Figures D10, D12 in Data in Brief) to week 12 
(Figures D11, D13 in Data in Brief). The majority of the CD3+ hyporesponsive proliferation shown by the scaffolds is therefore due to a decrease in the CD4+ proliferative response associated directly or indirectly with the presence of M2 monocytes. The macrophage polarization and abundance data indicate that both the $50 \mathrm{CC}$ and $50 \mathrm{CC}+\mathrm{H}$ scaffolds, with a greater thermo-responsive stiffness softening mechanism compared to the 50RTC $+\mathrm{H}$ samples, polarized infiltrating macrophages towards a regenerative phenotype, consistent with the matrix deposition and cellular infiltration patterns seen in these scaffold types.
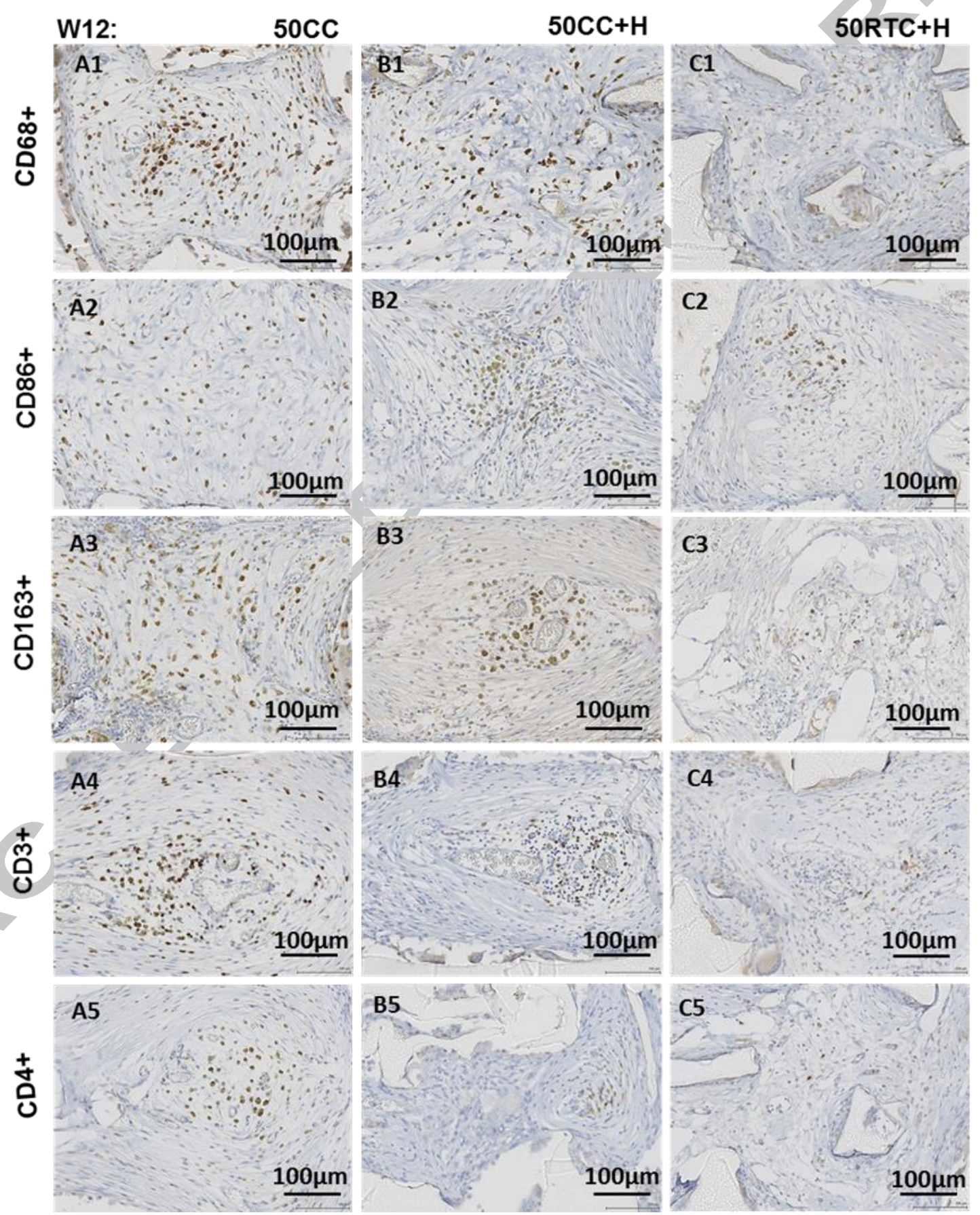
Figure 7 Immunohistochemistry of the host macrophage response in PUU-POSS scaffolds by 3D-TIPS with different thermal processing conditions. Week 12, tissue integration of middle-in-plane view of the scaffolds by CD68/CD86 (M1 marker), CD163 (M2 marker) and CD3/CD4 (T lymphocyte markers) staining. Scale bars: $100 \mu \mathrm{m}$.

A

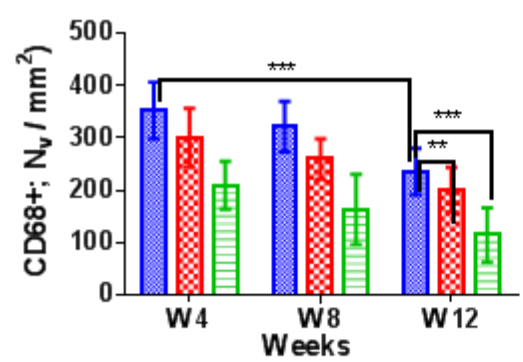

C

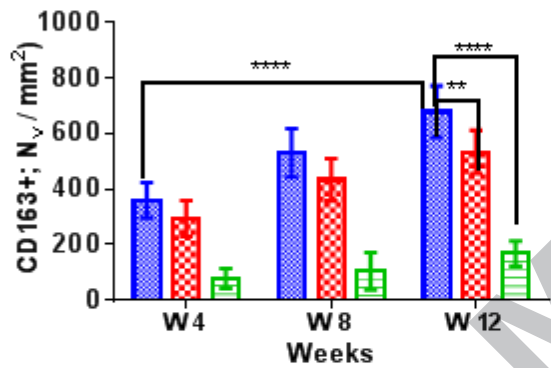

$\mathbf{E}$

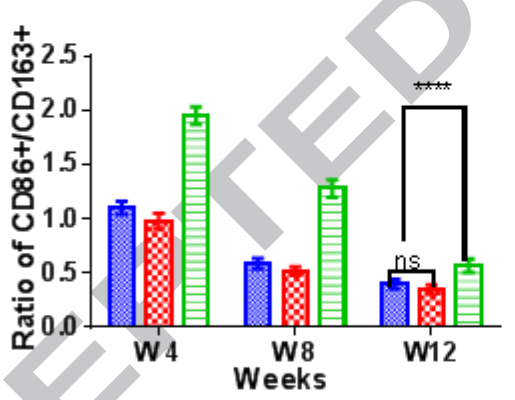

G

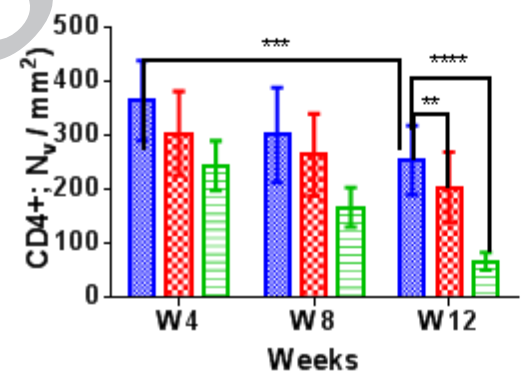

B

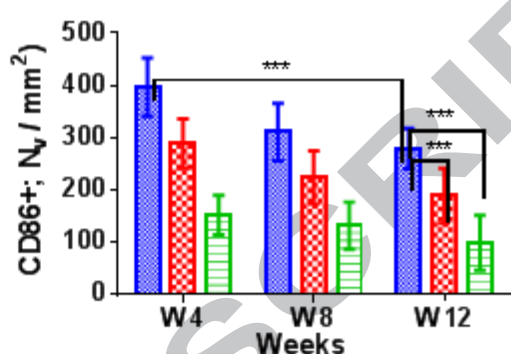

D

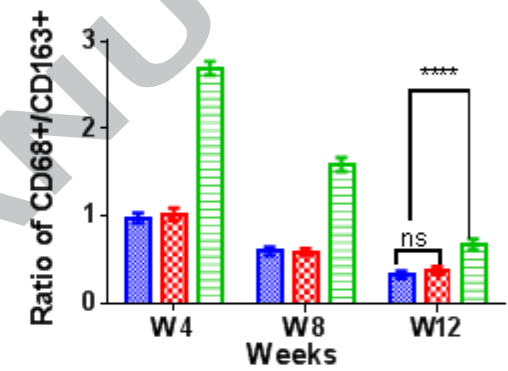

$\mathbf{F}$

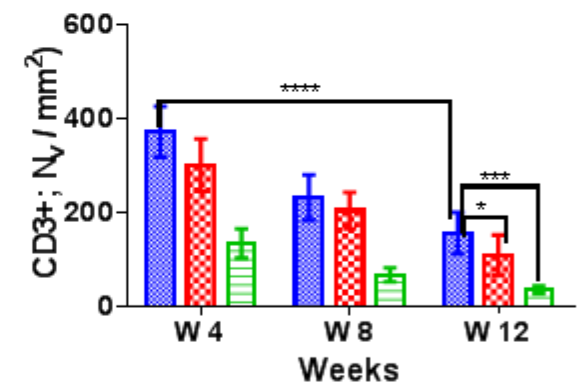

国 $50 C C$ 圈 $50 C C+H$ 目 $50 R T C+H$

Figure 8 Quantification of macrophage and T-cell response of PUU-POSS scaffolds by 3D-TIPS with different thermal processing conditions. Numerical density, as shown in the histogram, represents the number of cells across the scaffold per unit volume at weeks 4, 8 and 12; $\mathrm{n}=20$ frames, 12 scaffolds in each group at each time point: (A) M1 marker CD68+; (B) M1 marker CD86+, (C) M2 marker CD163+; (D) macrophage polarization $\mathrm{CD} 68+/ \mathrm{CD} 163+$; (E) macrophage polarization 
CD86+/CD163+; (F) T lymphocyte marker CD3+; (G) T lymphocyte marker CD4+. ${ }^{*} \mathrm{p}<0.05 ; * * \mathrm{p}<0.01 ; * * * \mathrm{p}<0.001 ; * * * * \mathrm{p}<0.0001$

\section{Discussion}

The thermoresponsive 'stiffness memory' through physical phase transition and self-assembly of soft and hard chain segments at body temperature of the non-degradable PUU-POSS scaffolds by 3D-TIPS [19] provides a unique 3D model system for understanding the stiffness softening effect on the behaviors of surrounding cells [29] and tissues without changing the polymer chemistry, such as chemical crosslinks or degradation. Three groups of the PUU-POSS scaffolds, 50CC, $50 \mathrm{CC}+\mathrm{H}$ and 50RTC $+\mathrm{H}$, were specifically designed and manufactured for understanding the effect of stiffness softening both in vitro and in vivo (Figure 1, Table D1-D3 in Data in Brief). Despite some variations in their porous structure, the low level or even little stiffness softening of 50CC+H and 50RTC+H scaffolds make them as meaningful control to understand the cellular responses to the stiffness softening of 50CC. The coupling effects between the stiffness softening and porous structure of the scaffolds can be further analyzed. One limitation that should be mentioned is that non-stiffness-softening samples with the same initial stiffness and porous structure as 50CC's cannot be achieved since the polymer chains are bound to relax at the body temperature regardless its initial status.

The in vitro study showed that the scaffolds promoted efficient attachment and proliferation of mouse fibroblasts within the porous structure, as demonstrated by quantitative cell viability tests, morphology and histological analysis (Figure 2). Cells were viable on all scaffolds, with the 50CC group exhibiting significantly $(\mathrm{p}<0.01)$ higher cellular activity during stiffness softening, as supported by metabolic activity, total DNA and extracellular collagen deposition assays. This is reminiscent of our previously reported results using human dermal fibroblasts [19].

The digitally printed interconnected macropores and channels of the scaffolds are adequate to facilitate tissue ingrowth and accommodate microvascularization (Figures 3-5) while keeping their overall structural integrity. Despite stiffness softening of the scaffolds, the tensile mechanical properties of the explants significantly $(p<0.0001)$ increased over time (Figure 3 D-G). The two main contributing factors to this were tissue ingrowth into the pores of the structures [30] and tissue remodeling via alignment of collagen fibres and elongated myofibroblasts in response to scaffolds mechanical changes (Figures 4-5, Figure D1 in Data in Brief). After 12 weeks implantation, non-significant differences in the tensile mechanical properties were observed between the different scaffold groups, which may be attributed to the post 'stiffness memory' effect that all the scaffolds relaxed to the same soft rubber phase within the first month. Similar to our previously reported in vitro study [19], cryo-3D-TIPS scaffolds (i.e. 50CC) with different starting stiffness gradually relaxed through melting of the semi-crystalline structure and inverse self-assembling to a quasi-random nanophase structure (Figure $3 \mathbf{H}-\mathbf{J}$ ), with softer 
hyperelasticity following implantation.

The initially higher matrix stiffness of the scaffolds with their subsequent relaxation, coupled with a suitable surface pore size (Table D1-D3 in Data in Brief), strongly influenced local tissue growth kinetics, corroborating in vitro data relating to cell attachment and proliferation (Figure 2). H\&E staining and collagen deposition showed that tissue grew into various anatomical structures following the geometry of the printed interconnected macro-framework tunnels in response to the local environment (Figures 4-5, Figures D2-D3 in Data in Brief), where short dumbbell tissue was seen growing in the joint tissue area, and aligned tissue grew along elongated horizontal tunnels. In particular, histological analysis demonstrated faster and greater aligned tissue ingrowth for the 50CC scaffolds. In addition to the geometry confinement, it is envisaged that these effects are due to local compression and local surface tension respectively [31,32]. Since 50CC and 50CC+H share similar morphology and porous structure, the different thickness of aligned tissue ingrowth between them may be mainly attributed to the stiffness softening. Porous structure may have more influence on the difference of the tissue between $50 \mathrm{CC}+\mathrm{H}$ and 50RTC $+\mathrm{H}$, which is not significant ( $\mathrm{p}>0.05)$ (Figures 4-5).

For a tissue to grow beyond the diffusion limit of oxygen (between 100 to $200 \mu \mathrm{m}$ ), the formation of new blood vessels is required [33]. The tissue reaction to the scaffolds included an efficient promotion of an angiogenic response, with the appearance of blood vessels as early as week 4 (Figure 6). The highest CVF was seen in the 50CC group, with 50RTC+H sample exhibiting the lowest CVF value. It is suggested that this greater microvascularization observed in the 50CC scaffold may be mainly promoted by a greater degree of stiffness relaxation, demonstrating the importance of the coherent scaffold-tissue stiffness matching. On the other hand, this phenomenon may also be contributed by a relatively broad hierarchy in the micro- to nano-porous structure of this scaffold group. The porous interconnectivity of scaffolds has been recognized to promote blood vessel invasion and facilitate tissue integration [34], as an appropriate macro- to micro- to nano- porosity is essential to allow nutrients to infiltrate and provide pathways for new blood vessel formation. The 50CC group, with its interconnected pores exhibited the densest capillary network generation during its stiffness relaxation period, significantly higher $(\mathrm{p}<0.0001)$ than that from $50 \mathrm{CC}+\mathrm{H}$ group with the similar porous structure, indicated that the initial high stiffness and subsequent stiffness softening may have a substantial influential role in angiogenesis (Figure $6 \mathbf{M}$ ). The lowest blood vessel count seen in the $50 \mathrm{RTC}+\mathrm{H}$ scaffolds may be due to the reduced surface micro-to nano-porous structure (Figure 1, Table D2-D3 in Data in Brief). This may reduce the surface area of the interfacial microenvironment and consequently, the diffusion of nutrients, metabolites and soluble factors throughout the scaffold. The difference of blood capillary count (Figure 4N) and CVF (Figure 6M) between $50 \mathrm{CCC}+\mathrm{H}$ and 50RTC $+\mathrm{H}$ with similar initial stiffness is less significant $(\mathrm{p}<0.05)$, which may reflect the moderate influence of uniformity and hierarchy of the porous structure of the 
scaffold on the blood vessel growth. Nevertheless, while significantly greater vascularization was observed after 3 months in all implanted scaffolds after full stiffness relaxation, further work needs to address whether this phenomenon relates to ingrowth of existing blood capillaries within the porous structure or due to true de novo angiogenesis.

On the other hand, the highly plastic inflammatory macrophage phenotype can also profoundly influence regeneration by altering the fibrotic [35]. A reduced inflammatory response is one of the factors required for scar less wound healing and reduced fibrosis formation in implants [36], and the predominant phenotype of resident macrophages can provide an indication of the scaffold rejection (inflammation) or acceptance following implantation and determine the stage of wound healing [37]. While M1 macrophages are known to express high levels of interleukins and pro-inflammatory cytokines that promote inflammation, M2 macrophages express low levels of these and are able to facilitate and promote tissue repair [38]. It has been shown that the mechanical and topological properties of the scaffolds can regulate macrophage responses [17,39,40]. Macrophages have also been demonstrated to sense their underlying substrate stiffness: higher macrophage cell spreading and attachment is seen on stiffer substrates, leading to a more severe foreign body reaction, while softer substrates promote M2-like macrophage activation towards a wound healing phenotype [41-43]. Despite the difference between each scaffold type, the overall trend of the inflammatory response is similar with a decrease of M1 microphages and T-cells, and a decrease of M2 microphages from week 4 to week 12 implantation (Figure 8). The initial high stiffness and subsequential stiffness softening of the 50CC scaffold appeared to trigger more M1 and M2 macrophages as well as $\mathrm{T}$ cells from the early stage of implantation, compared to $50 \mathrm{CC}+\mathrm{H}$ and 50RTC $+\mathrm{H}$. By the 12 weeks of implantation, the difference between 50CC and $50 \mathrm{RTC}+\mathrm{H}$ is less significant as with $50 \mathrm{RTC}+\mathrm{H}$ after the long stiffness softening, indicating that the morphology and porous structure of the scaffolds also have a strong influence on the inflammatory response.

The stiffness softening effect of the scaffolds on macrophage polarization was therefore investigated. Macrophage polarization from an M1 towards an M2 phenotype was observed within all implanted scaffolds, as evidenced by the reduction of CD68+ and CD86+ cells from week 4 towards week 12 (Figure 8 A-B) and the increase of CD163+ (Figure 8C) in the scaffolds. In addition, the M1/M2 ratio was found to be lower for both the 50CC and 50CC+H groups than 50RTC+H scaffolds at all time points (Figure $8 \mathrm{D}-\mathrm{E}$ ). The difference of M1/M2 between 50CC and $50 \mathrm{CC}+\mathrm{H}$ became non-significant. It is here suggested that the stiffness relaxation effect and hierarchical porous structure exhibited by the 50CC and 50CC+H scaffolds plays a coherent role in local inflammatory response modulation and could be used as a significant parameter to aid macrophage M1 to M2 polarization. The findings of macrophage polarization are also supported by an attenuated in vivo proliferation of CD3+ and CD4+ T-cell subsets at 12 weeks (Figure 8 F-G) compared to week 4. 
Prolonged in vivo implantation periods should be explored, as should detection and quantification of inhibitory and pro-inflammatory cytokine levels. In addition, quantitative PCR of Wnt-related genes could be studied, as the Wnt signaling pathway is known to be a key mechanotransduction pathway in fibroblast regulation of wound healing [44]. Another point to bear in mind in a future study is that regarding the interplay of mechanosensing proteins (e.g. vinculin, talin, tensin, caveolin-1, $\beta 1$ integrin...) [45-47] with regards to the stiffness softening of the scaffolds. The turnover rate of mechanosensing proteins is affected by changes in the substrate stiffness, ultimately regulating the cell's cytoskeleton and function. However, the exact mechanisms of how matrix stiffness and substrate elasticity controls theses protein levels are still unclear.

\section{Conclusion}

The digitally programmed shape and interconnected macro/micro-interconnected porous structure of the thermoresponsive elastomeric PUU-POSS scaffolds by 3D-TIPS have been shown to guide and promote interfaces for tissue ingrowth and the formation of functional microvascular networks. In concordance with our recently-reported in vitro study, the stiffness softening, induced by physical phase transition and self-assembly of soft and hard chain segments of PUU chains, has been found to promote in vitro and in vivo cell adhesion and proliferation, tissue ingrowth and vascularization, with no changes in molecular structure of the scaffold.

This 'stiffness memory' softening effect together with the hierarchical porous structure were seen to modulate tissue ingrowth in several ways and to reduce in vivo inflammation in a rat model for up to 12 weeks, with enhanced polarization towards the macrophage M2 phenotype. The observations indicate that the stiffness softening demonstrated by the 3D-TIPS PUU-POSS scaffolds could prove an effective route to regulate a host regenerative vs. scarring phenotype, while matching the mechanical properties of the surrounding soft tissue and improving tissue integration and healing after implantation.

\section{Acknowledgements}

The authors acknowledge financial support by the Engineering and Physical Science Research Council (EPSRC), the United Kingdom, grants No. EP/L020904/1, EP/M026884/1 and EP/R02961X/1210

\section{Conflict of interests}

The authors declare no potential conflict of interests with respect to the research, authorship and/or publication of this article.

\section{References}


[1] R.A. Hortensius, J.H. Ebens, B.A.C. Harley, Immunomodulatory effects of amniotic membrane matrix incorporated into collagen scaffolds, J. Biomed. Mater. Res. A. 104 (2016) 1332-1342. doi:10.1002/jbm.a.35663.

[2] W.D. Merryman, I. Youn, H.D. Lukoff, P.M. Krueger, F. Guilak, R.A. Hopkins, M.S. Sacks, Correlation between heart valve interstitial cell stiffness and transvalvular pressure: implications for collagen biosynthesis, Am. J. Physiol. Heart Circ. Physiol. 290 (2006) H224-231. doi:10.1152/ajpheart.00521.2005.

[3] M. Guvendiren, J.A. Burdick, Stiffening hydrogels to probe short- and long-term cellular responses to dynamic mechanics, Nat. Commun. 3 (2012) 792. doi:10.1038/ncomms1792.

[4] M.F. Griffin, Y. Premakumar, A.M. Seifalian, M. Szarko, P.E.M. Butler, Biomechanical characterisation of the human auricular cartilages; implications for tissue engineering, Ann. Biomed. Eng. 44 (2016) 3460-3467. doi:10.1007/s10439-016-1688-1.

[5] S.A. Eming, T. Krieg, J.M. Davidson, Inflammation in wound repair: molecular and cellular mechanisms, J. Invest. Dermatol. 127 (2007) 514-525. doi:10.1038/sj.jid.5700701.

[6] R.F. Diegelmann, M.C. Evans, Wound healing: an overview of acute, fibrotic and delayed healing, Front. Biosci. J. Virtual Libr. 9 (2004) 283-289.

[7] C.A. Engh, J.D. Bobyn, A.H. Glassman, Porous-coated hip replacement. The factors governing bone ingrowth, stress shielding, and clinical results, J. Bone Joint Surg. Br. 69 (1987) 45-55.

[8] M. Rumpler, A. Woesz, J.W.. Dunlop, J.T. van Dongen, P. Fratzl, The effect of geometry on three-dimensional tissue growth, J. R. Soc. Interface. 5 (2008) 11731180. doi:10.1098/rsif.2008.0064.

[9] R. Weigert, Implanted biomaterials: Dissecting fibrosis, Nat. Biomed. Eng. 1 (2017) s41551-016-0016-016. doi:10.1038/s41551-016-0016.

[10]W. Sun, B. Starly, J. Nam, A. Darling, Bio-CAD modeling and its applications in computer-aided tissue engineering, Comput.-Aided Des. 37 (2005) 1097-1114. doi:10.1016/j.cad.2005.02.002.

[11] G.M. de Peppo, A. Palmquist, P. Borchardt, M. Lennerås, J. Hyllner, A. Snis, J. Lausmaa, P. Thomsen, C. Karlsson, Free-form-fabricated commercially pure Ti and Ti6Al4V porous scaffolds support the growth of human embryonic stem cell-derived mesodermal progenitors, ScientificWorldJournal. 2012 (2012) 646417. doi:10.1100/2012/646417.

[12]C. Zgheib, J. Xu, K.W. Liechty, Targeting inflammatory cytokines and extracellular matrix composition to promote wound regeneration, Adv. Wound Care. 3 (2014) 344-355. doi:10.1089/wound.2013.0456. 
[13]B.J. Larson, M.T. Longaker, H.P. Lorenz, Scarless fetal wound healing: a basic science review, Plast. Reconstr. Surg. 126 (2010) 1172-1180. doi:10.1097/PRS.0b013e3181eae781.

[14]O.O. Olutoye, D.R. Yager, I.K. Cohen, R.F. Diegelmann, Lower cytokine release by fetal porcine platelets: a possible explanation for reduced inflammation after fetal wounding, J. Pediatr. Surg. 31 (1996) 91-95.

[15]O.O. Olutoye, X. Zhu, D.L. Cass, C.W. Smith, Neutrophil recruitment by fetal porcine endothelial cells: implications in scarless fetal wound healing, Pediatr. Res. 58 (2005) 1290-1294. doi:10.1203/01.pdr.0000184326.01884.bc.

[16]B. Naik-Mathuria, A.N. Gay, X. Zhu, L. Yu, D.L. Cass, O.O. Olutoye, Age-dependent recruitment of neutrophils by fetal endothelial cells: implications in scarless wound healing, J. Pediatr. Surg. 42 (2007) 166-171. doi:10.1016/j.jpedsurg.2006.09.058.

[17]F.Y. McWhorter, C.T. Davis, W.F. Liu, Physical and mechanical regulation of macrophage phenotype and function, Cell. Mol. Life Sci. CMLS. 72 (2015) 13031316. doi:10.1007/s00018-014-1796-8.

[18]B. Smitha, M. Donoghue, Clinical and histopathological evaluation of collagen fiber orientation in patients with oral submucous fibrosis, J. Oral Maxillofac. Pathol. JOMFP. 15 (2011) 154-160. doi:10.4103/0973-029X.84481.

[19]L. Wu, J. Virdee, E. Maughan, A. Darbyshire, G. Jell, M. Loizidou, M. Emberton, P. Butler, A. Howkins, A. Reynolds, I. Boyd, M. Birchall, W. Song, Stiffness memory nanohybrid scaffolds generated by indirect 3D printing for biologically responsive soft implants, Acta biomaterialia. (2018). doi:10.1016/j.actbio.2018.09.016.

[20]C. Mota, D. Puppi, F. Chiellini, E. Chiellini, Additive manufacturing techniques for the production of tissue engineering constructs, J. Tissue Eng. Regen. Med. 9 (2015) 174-190. doi:10.1002/term.1635.

[21]E.S. Bishop, S. Mostafa, M. Pakvasa, H.H. Luu, M.J. Lee, J.M. Wolf, G.A. Ameer, T.-C. He, R.R. Reid, 3-D bioprinting technologies in tissue engineering and regenerative medicine: Current and future trends, Genes Dis. 4 (2017) 185195. doi:10.1016/j.gendis.2017.10.002.

[22]A. Asefnejad, M.T. Khorasani, A. Behnamghader, B. Farsadzadeh, S. Bonakdar, Manufacturing of biodegradable polyurethane scaffolds based on polycaprolactone using a phase separation method: physical properties and in vitro assay, Int. J. Nanomedicine. 6 (2011) 2375-2384. doi:10.2147/IJN.S15586.

[23]T. Lu, Y. Li, T. Chen, Techniques for fabrication and construction of three-dimensional scaffolds for tissue engineering, Int. J. Nanomedicine. 8 (2013) 337-350. doi:10.2147/IJN.S38635. 
[24]M. Pezeshki-Modaress, S. Rajabi-Zeleti, M. Zandi, H. Mirzadeh, N. Sodeifi, A. Nekookar, N. Aghdami, Cell-loaded gelatin/chitosan scaffolds fabricated by salt-leaching/lyophilization for skin tissue engineering: in vitro and in vivo study, J. Biomed. Mater. Res. A. 102 (2014) 3908-3917. doi:10.1002/jbm.a.35054.

[25]M. Mehrabanian, M. Nasr-Esfahani, HA/nylon 6,6 porous scaffolds fabricated by salt-leaching/solvent casting technique: effect of nano-sized filler content on scaffold properties, Int. J. Nanomedicine. 6 (2011) 1651-1659. doi:10.2147/IJN.S21203.

[26]R.Y. Kannan, H.J. Salacinski, M. Odlyha, P.E. Butler, A.M. Seifalian, The degradative resistance of polyhedral oligomeric silsesquioxane nanocore integrated polyurethanes: An in vitro study, Biomaterials. 27 (2006) 1971-1979. doi:10.1016/j.biomaterials.2005.10.006.

[27]M. Molnar, P. Friberg, Y. Fu, M. Brisslert, M. Adams, Y. Chen, Effects of Quantum Dot Labeling on Endothelial Progenitor Cell Function and Viability, Cell Med. 1 (2010) 105-112. doi:10.3727/215517910X451603.

[28]R. Rage, J. Mitchen, G. Wilding, DNA fluorometric assay in 96-well tissue culture plates using Hoechst 33258 after cell lysis by freezing in distilled water, Anal. Biochem. 191 (1990) 31-34. doi:10.1016/0003-2697(90)90382-J.

[29]L. Wu, A. Magaz, T. Wang, C. Liu, A. Darbyshire, M. Loizidou, M. Emberton, M. Birchall, W. Song, Stiffness memory of indirectly 3D-printed elastomer nanohybrid regulates chondrogenesis and osteogenesis of human mesenchymal stem cells, Biomaterials. (2018). doi:10.1016/j.biomaterials.2018.09.013.

[30]R. Hedayati, S. Janbaz, M. Sadighi, M. Mohammadi-Aghdam, A.A. Zadpoor, How does tissue regeneration influence the mechanical behavior of additively manufactured porous biomaterials?, J. Mech. Behav. Biomed. Mater. 65 (2017) 831-841. doi:10.1016/j.jmbbm.2016.10.003.

[31]D. Vader, A. Kabla, D. Weitz, L. Mahadevan, Strain-Induced Alignment in Collagen Gels, PLoS ONE. 4 (2009). doi:10.1371/journal.pone.0005902.

[32]A. Tondon, R. Kaunas, The Direction of Stretch-Induced Cell and Stress Fiber Orientation Depends on Collagen Matrix Stress, PLoS ONE. 9 (2014). doi:10.1371/journal.pone.0089592.

[33]P. Carmeliet, R.K. Jain, Angiogenesis in cancer and other diseases, Nature. 407 (2000) 249-257. doi:10.1038/35025220.

[34]X. Xiao, W. Wang, D. Liu, H. Zhang, P. Gao, L. Geng, Y. Yuan, J. Lu, Z. Wang, The promotion of angiogenesis induced by three-dimensional porous beta-tricalcium phosphate scaffold with different interconnection sizes via activation of PI3K/Akt pathways, Sci. Rep. 5 (2015) 9409. doi:10.1038/srep09409. 
[35]A. Das, M. Sinha, S. Datta, M. Abas, S. Chaffee, C.K. Sen, S. Roy, Monocyte and macrophage plasticity in tissue repair and regeneration, Am. J. Pathol. 185 (2015) 2596-2606. doi:10.1016/j.ajpath.2015.06.001.

[36]A. Sindrilaru, K. Scharffetter-Kochanek, Disclosure of the culprits: macrophages-versatile regulators of wound healing, Adv. Wound Care. 2 (2013) 357-368. doi:10.1089/wound.2012.0407.

[37]J.M. Daley, S.K. Brancato, A.A. Thomay, J.S. Reichner, J.E. Albina, The phenotype of murine wound macrophages, J. Leukoc. Biol. 87 (2010) 59-67.

[38]R. Sridharan, A.R. Cameron, D.J. Kelly, C.J. Kearney, F.J. O'Brien, Biomaterial based modulation of macrophage polarization: a review and suggested design principles, Mater. Today. 18 (2015) 313-325. doi:10.1016/j.mattod.2015.01.019.

[39]K. Garg, N.A. Pullen, C.A. Oskeritzian, J.J. Ryan, G.L. Bowlin, Macrophage functional polarization (M1/M2) in response to varying fiber and pore dimensions of electrospun scaffolds, Biomaterials. 34 (2013) 4439-4451. doi:10.1016/j.biomaterials.2013.02.065.

[40]R. Guo, A. Merkel, J. Sterling, J. Davidson, S. Guelcher, Substrate modulus of 3d-printed scaffolds regulates the regenerative response in subcutaneous implants through the macrophage phenotype and wnt signaling, Biomaterials. 73 (2015) 85-95. doi:10.1016/j.biomaterials.2015.09.005.

[41]S. Féréol, R. Fodil, B. Labat, S. Galiacy, V.M. Laurent, B. Louis, D. Isabey, E. Planus, Sensitivity of alveolar macrophages to substrate mechanical and adhesive properties, Cell Motil. Cytoskeleton. 63 (2006) 321-340. doi:10.1002/cm.20130.

[42]A.K. Blakney, M.D. Swartzlander, S.J. Bryant, The effects of substrate stiffness on the in vitro activation of macrophages and in vivo host response to poly(ethylene glycol)-based hydrogels, J. Biomed. Mater. Res. A. 100 (2012) 1375-1386. doi:10.1002/jbm.a.34104.

[43]T. Okamoto, Y. Takagi, E. Kawamoto, E.J. Park, H. Usuda, K. Wada, M. Shimaoka, Reduced substrate stiffness promotes M2-like macrophage activation and enhances peroxisome proliferator-activated receptor $\gamma$ expression, Exp. Cell Res. (n.d.). doi:10.1016/j.yexcr.2018.04.005.

[44]M.V. Barbolina, Y. Liu, H. Gurler, M. Kim, A.A. Kajdacsy-Balla, L. Rooper, J. Shepard, M. Weiss, L.D. Shea, P. Penzes, M.J. Ravosa, M.S. Stack, Matrix rigidity activates Wnt signaling through down-regulation of Dickkopf-1 protein, J. Biol. Chem. 288 (2013) 141-151. doi:10.1074/jbc.M112.431411.

[45]K.A. Jansen, P. Atherton, C. Ballestrem, Mechanotransduction at the cell-matrix interface, Semin. Cell Dev. Biol. 71 (2017) 75-83. doi:10.1016/j.semcdb.2017.07.027.

[46]K. Hayakawa, H. Tatsumi, M. Sokabe, Mechano-sensing by actin filaments and 
focal adhesion proteins, Commun. Integr. Biol. 5 (2012) 572-577. doi:10.4161/cib.21891.

[47]Y.-C. Yeh, J.-Y. Ling, W.-C. Chen, H.-H. Lin, M.-J. Tang, Mechanotransduction of matrix stiffness in regulation of focal adhesion size and number: reciprocal regulation of caveolin-1 and $\beta 1$ integrin, Sci. Rep. 7 (2017) 15008. doi:10.1038/s41598-017-14932-6. 


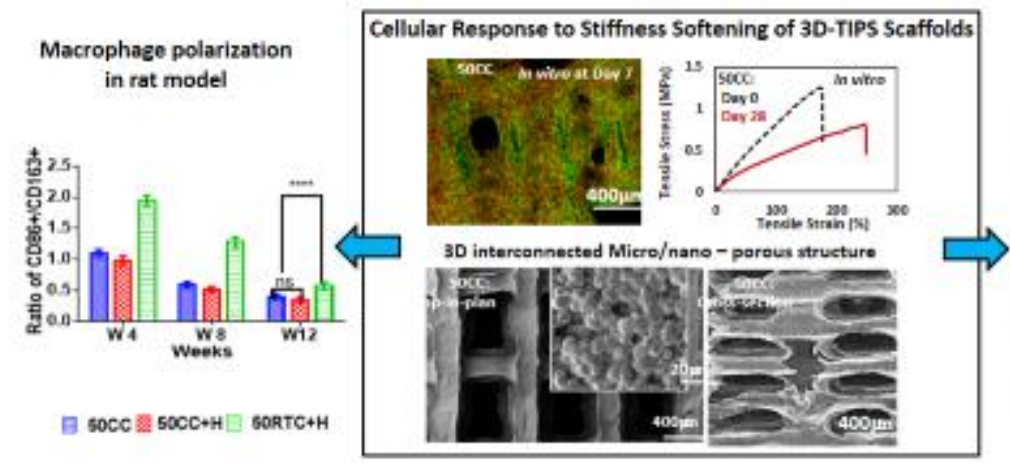

Vascularization

in rat model

$50 C \mathrm{CW12} \quad \mathrm{CD} 3 \mathrm{II}_{1}$
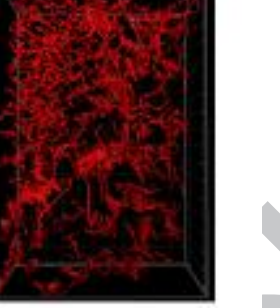